by L. D. Wedeven

Lewis Research Center

Cleveland, Ohio

and

C. Cusano

University of Illinois

Urbana, Illinois

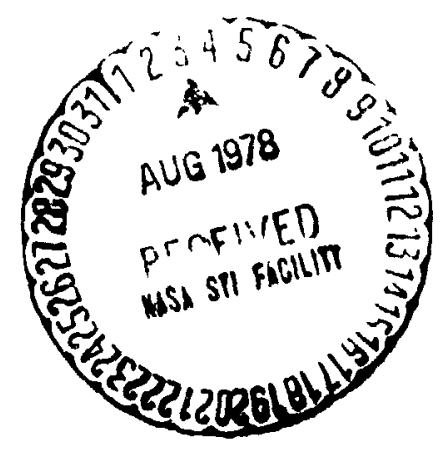

TECHNICAL PAPER to be presented at the Joint Lubrication Conference cosponsored by the American Society of Mechanical Engineers and the American Society of Lubrication Engineers Minneapolis, Minnesota, October 24-26, 1978 


\title{
I LASTOHYDRODYNAMIC FILM THICKNESS MEASUREMENTS OF ARTIFICIALLY PRODUCED SURFACE DENTS AND GROOVES
}

\author{
by L. D. Wedeven \\ National Aeronautics and Space Administration \\ Lewis Research Center \\ Cleveland, Ohio $44 \mathrm{i} 35$ \\ and \\ C. Cusano \\ University of Illinois \\ Urbana, Illinois 61801
}

\begin{abstract}
Elastohydrodynamic (EHD) film thickness measurements using optical interferometry have been made of artificially produced dents and grooves under rolling and sliding conditions. These measurements are compared to stylus traces of the dent and groove profiles to determine the local deformation associated with micro-EHD pressure generation. The surface geometry associated with the dents and grooves is seen to become intimately involved in the lubrication process itself, creating local pressure variations that substantially deform the local surface geometry, particularly under sliding conditions. The rolling results have implications concerning surface initiated fatigue anc' the sliding results show clearly the EHD surface interactions that must, occur prior to scuffing failure.
\end{abstract}




\title{
ELASTOHYDFODYNAMIC FILM THICKNESS MEASUREMENTS OF \\ ARTIFICIALLY PRODUCED SURFACE DENTS AND GROOVES
}

\author{
by L. D. Wedeven \\ National Aeronautics and Space Administration \\ Lewis Research Center \\ Cleveland, Ohio : 135 \\ and \\ C. Cusano \\ University of Illinois \\ Urbana, Illinois 61801 \\ INTRODUCTION
}

Fatigue failures of mechanical elements which operate in concentrated contacts are usually divided into subsurface- and surface-originated failures. With the advent of vacuum-melted steels, nonmetallic inclusions which are usually responsible for subsurface failures have been considerably reduced (1). This reduction has resulted in fewer subsurface-originated fatigue failures and, as a consequence, recent research efforts have concentrated mainly on surface-originated fatigue failures (1-4). Surface-originated fatigue failures are generally caused by localized defects such as furrows and dents and by pits which have been caused by a distress of surface asperities. Since it is believed that surfaces are pitted at the very beginning of their fatigue life, these pits can also be considered as defects similar to furrows and dents.

One of the basic problems that needs to be solved before surface-originated fatigue failures can be more fully understood is the determination of stresses around suriace defects as these defects pass through lubricated, heavily loaded contacts. Before the specific purpose of this paper is defined a brief background on the lubrication of rough surfaces will be given.

The first known analytical study on the hydrodynamic lubrication of surfaces having random roughness was done by Tseng and Saibel (5). Their analysis was based on only a one-dimensional transverse model of roughness. Christensen and his colleagues (6-9) have analytically investigated the hydrodynamic lubrication of both transverse and longitudinal one-dimensional models of rough surfaces. Other analytical studies on the hydrodynamic lubrication of rough surfaces have been done by Tonder and 
Christensen (10), Tonder (11), Sun and Chen (12), and Rhow and Elrod (13). Even though references 5 to 13 assumed hydrodynamic lubrication, the results obtained contributed significantly to the understanding of the lubrication characteristics of rough surfaces. Among the analytical studies on the effects of rough surfaces on EHD lubrication are those of Chow and Cheng (14), Li, Kauzlarich and Jamison (3), Johnson, Greenwood, and Poon (15), and Tallian (2). Idealized single-surface defects in EHD sliding contact have been studied by Chiu (4) and EHD lubrication of idealized asperities has been analytically investigated by Chow and Cheng $(16)$ and Fowles $(17,18)$.

Some of the more important results of the analytical studies mentioned above are:

(1) The effects of surface roughness on the operating characteristics of lubricated. mechanical elements are negligible when the mean separation of the sliding or rolling surfaces is large compared to the height of the roughness.

(2) For the same operating conditions, transverse one-dimensional roughness results in thicker oil-films than longitudinal one-dimensional roughness.

(3) There are very high stress concentrations developed around the edges of defec.s when these defects are in the EHD Hertzian contact.

(4) Surface asperities can be almost completely flattened within the Hertzian conjunction under pure sliding conditions.

(5) Local EHD effects around an asperity are less significant when the surfaces are subjected to pure rolling than when they are subjected to pure sliding.

(6) Very high pressures and temperatures can be developed between colliding asperities.

These and other significant analytical findings have recently resulted in greater efforts than in the past to experimentally study the lubrication of rough surfaces. Among the more related experimenta! studies have been those of Jackson and Cameron (19) and Wedeven (20). In reference 19 optical interferometry was used to study artificially-produced grooves on a polished ball under sliding conditions. The grooves which were held stationary were oriented in both the transverse and longitudinal directions relative to the sliding direction of a transparent surface so that the effects of directional properties of roughness on EHD lubrication could be studied. In reference 20 a debris dent was studied as it passed through the conjunction region under 
rolling conditions. As done in reference 19 these studies were done by means of optical interferometry. Unlike the artificially-prod، sed defects studied in reference 19, the dent studied in reference 20 was formed naturally during previous testing. In general, the limited experimental findings reported in references 19 and 20 agreed with the general trends of previous analytical investigations. However, experimental measurements of defects of different size and orientation under both rolling and sliding conditions have not been adequately investigated.

In the present study, optical interferometry is used to investigate the effects of artificially-p1'duced dents and grooves, on highly-polished balls, on the EHD film thickness in Hertzian contact. The artificially-produced defects geometrically approximate actual furrows and dents found in bearings and gears.

The purpose of this investigation is to present film thickness measurements associated with artificially-produced grooves and dents in Hertzian contacts, to show how these artificially-produced defects become intrinsically involved in the micro-EHD lubrication process itself, and to indicate the implication of these defects on fatigue failure.

\section{EXPERIMENTAL APPARATUS}

Film thickness measurements were made using optical interferometry. The optical elastohydrodynamic apparatus is shown in figure 1 and described in detail elsewhere $(21,22)$. The basic components. of the apparatus consist of a ball which rides against a transparent disk.

The EHD film thickness between these surfaces was measlired by optical interferometry. Fringes of very good visibility were obtained by using a 17-percent-reflecting layer of chromium on the bearing surface of the transparent disk. Interference measurements were made with wavelengths of two colors (red and green). These were ubtained by using a special filter and a xenon flash lamp as a light source. The details of this system and its calibration are described more fully in references 23 and 24. All measurements were carried out at room temperature $\left(23^{\circ} \mathrm{C}\right)$.

\section{TEST MATERIALS}

The test bearing specimens are shown in figure 2. The ball is 0.02063 meter in diameter and made of AISI 52100 steel. Its nominal surface roughness is better 
than $0.018 \mu \mathrm{m} \mathrm{rms}(0.7 \mu \mathrm{in}$.$) and its hardness is approximately 65 \mathrm{R}_{\mathrm{c}}$. Other mechanical properties are shown in table 1. The transparent disk is 0.102 meter in diameter and made of sapphire. Its mechanical properties are given in table 1 .

The test ball was supported by three bearings located in a lubricant reservoir shown in figure 2 . The rotation of the support bearings continuously supplies lubricant to the test ball.

The tests were performed with a synthetic paraffinic oil that was designated by the manufacturer as XRM 109F3. The properties of the test fluid are given in table II.

\section{FORMATION OF ARTIFICIAL DEFECTS}

As stated in the introduction, surface-originated fatigue failures are generally caused by localized defects such as furrows and dents. Since it was decided to investigate such defects as they passeci through the EHD Hertzian contact by using optical interferometry, film thickness measurements in the vicinity of the defects could only be made if the surface around and inside the defects was highly polished. Film thickness measurements on real surfaces, such as those found on gears and bearings, could not be easily made by means of optical interferometry because it would have been difficult to obtain visible and continuous fringes. This difficulty stems from the fact that, on such surfaces, the asperities are relatively steep-sloped and closely spaced, thus causing the fringes to merge or disappear because of the limited resolution of the microscope used to observe them. It was necessary, therefore, to artificially-produce surface defects on highly-polished balls. The geometry of the artificially-produced defects was approximately equal to the geometry of furrows and dents commonly found on surfaces of bearings $(25-28)$.

The defects were produced by using carbide tools. With such tools, many defects could be produced on the surface of the softer balls without altering the initial tip geometry of the tools. A total of four tools were used. Two with a conical geometry to produce defects which simulated dents in real surfaces and two with a wedge geometry to produce defects which simulated furrows in real surfaces. The reason for making two tools for each defect geometry was to obtain different bluntness on the tip of the tools so that size and depth of defects could be varied. Before the defects were produced, the ground conical and wedge portions of the carbide tools were highly hand- 
polished by using a fine diamond compound. By polishing the tools it was found that their tip would deform the surface of the balls without tearing or roughening 'he surface, thus insuring visible fringes for film-thickness measurements.

A simple fixture was designed to facilitate the formation of dents and grooves in the polished ball. The sizes of the dents and grooves were controlled by the bluntness of the tools and the load used to produce them. The load was applied directly to the tools by means of weights, and the tools were guided to reduce positioning problems. To insure a series of geometrically uniform grooves or dents, it was essential that the weights be gradually brought into contact with the tools so that no impact loading took place between the weights and the tools. The depths of the deforts were generally less than $2 \mu \mathrm{m}$ and the widths less than $80 \mu \mathrm{m}$.

\section{RESULTS}

Experimental results will be presented in the form of:

(1) Photomicrographs of interference fringes showing the film thickness distribution in the vicinity of the defects under static, rolling and sliding conditions

(2) Cross-sectional plots of the film thickness distribution inside and around the defects as observed from the photomicrographs

(3) Stylus traces of the "undeformed" geometry of the defects. The purpose of these traces is to compare the "undeformed" geometry of the defects to the geometry of the same defects observed under static and dynamic conditions.

\section{SINGLE DENT}

Figure 3 shows an artificially-produced dent obtained with a $44.5 \mathrm{~N}$ (10 lbf) load on a cone-shaped carbide tool. The geometric features of the dent are obtained from stylus traces. The styl'is is rotated about an axis concentric with the ball center so that the ball curvature could be eliminated. Eleven passes across the dent at equally spaced intervals have been recorded. Figure 4 shows a stylus trace through the deepest portion of the dent. This trace is selected for measirement purposes. The dent is very shallow, being 100 times wider than it is deep. (An estimate of the maximum Hertzian pressure between the tool and ball was made using a radius of curvature, calculated from the stylus trace, of $0.125 \mathrm{~cm}$. For this radius of curvature, the estimated maximum Hertzian pressure is $5.4 \times 10^{9} \mathrm{~N} / \mathrm{m}^{2}(780000 \mathrm{psi})$. It is interesting 
that many accelerated fatigue test.s are run at similar pressures.) Its width is appruximately $100 \mu \mathrm{m}$ and its depth is $1 \mu \mathrm{m}$. A slight buildup of material around the dent shoulders can be seen from the stylus traces. This dent is very similar to the debris dent studied in a previous publication (20).

The stylus trace provides a reference profile which gives the geometry of the dent in its undeformed condition. It can be thought of as representing th: shape of the dent that would be expected if the influence of EHD has created a pressure environment around the dent which allows the dent to pass through the Hertzian region in an "undeformed" state; that is, the pressure around the dent is everywhere equal to the Hertzian pressure for smcoth surfaces.

A second reference profile is the static profile which is obtained from the interference fringes formed when the dent, in the Hertzian contact region, is loaded under static contact conditions as shown in figure 5. The load used for all tests was $37.8 \mathrm{~N}(8.5 \mathrm{lbf})$ giving a maximum Hertzian pressure of $1.13 \times 10^{9} \mathrm{~N} / \mathrm{m}^{2}(163000 \mathrm{psi})$. The Hertzian diameter is $254 \mu \mathrm{m}$ which is approximately $2 \frac{1}{2}$ times the diameter of the dent.

From the fringe pattern shown in figure 5 , the static profile of the dent can be generat?d. Such a profile is shown in figure 6 along with the undeformed profile from the stylus trace. The load is seen to deform the dent so that the maximum surface separation is 25 percent smaller than the depth of the undeformed dent.

SINGLE DENT - ROLLING

Observations were made of the dent as it passed through the conjunction region. This was accomplished by taking high-speed single flash photomicrographs. The xenon flash lamp was synchronized with the ball rotation and could be delayed so that the dent could be photographed in various positions within the conjunction region. When the dent passes through the Hertzian region, the first portion of the dent to enter is called the leading edge and the last portion to enter is called the trailing edge. Thus, when a dent is observed in the Hertzian region the edge of the dent closest to the inlet region is the trailing edge and the edge of the dent closest to the exit region is the leading edge.

The observations made on the present artificially-produced dent under pure rolling conditions substantiated the results obtained in reference 20 for a debris dent. Under 
dynamic conditions the amount of elastic deformation associated with the dent varies with the central film thickness. As the central film thickness increases the dent approaches its uncieformed shape.

A reduction in film thickness occurs at the leading edge of the dent. This reduction is caused by the local EHD pressure modification the dent has created during its passage through the inlet region.

The measurement of the dent profile under increasing film thickness conditions leads to the impliration that the pressure and stress conce.ttration associated with the shoulders of the dent is gradually relieved as the film thickness increases. In addition, the leading edge of the dent is relieved to a greater extent than the trailing edge.

\section{SINGLE DENT - SLIDING}

Under pure rolling conditions it was found that the film thickness distribution remained fixed as the dent passed through the Hertzian region. When sliding is introduced, substantial micro-EHD pressures are generated as the dent passes through the Hertzian region. This is shown in figure 7 (a), (b), and (c) where the dent is moving and the smooth sapphire surface is stationary. The converging and diverging regions of the moving dent enhance and diminish respectively the local pressure at these sites. Consequently as the dent passes through the Hertzian region the pressure and film thickness are reduced within the dent and increased spectacularly ai the trailing edge of the dent. This increase in film thickness leaves a pressure "tail" which progressively lags the dent as it passes through the Hertzian region. This can be seen in the photomicrographs of figure 7 (a), (b), and (c) and the corresponding cross-sectional plots of figure 8(a), (b), and (c). Note that film thickness in the "tail" is approximately double the nominal film thickness for smooth surfaces. Figures $7(c)$ and $8(c)$ show the pressure tail momentarily in the Hertzian region while the dent has disappeared into the exit region.

Figure 9(a) compares the dent profiles for rolling and sliding conditions and figure 9 (b) compares the sliding profile with the static profile. Substantial elastic deformation is seen at the trailing edge of the dent which implies high pressure and stress concentration in this region. This is in line with the very high pressures predicied by 
Lee and Cheng (29) and Fowles (17) at asperity sites and the pressure rippling predicted by Tallian (30).

In addition, the results obtained under sliding conditions, which show an increase in pressure trailing the dent along with the apparent decrease in pressure within the dent, are in general agreement with recent transient temperature measurements made by Winer and Sanborn (31). They found that when asperity "contact" started to occur the peak temperature fluctuation increased as expected; but, in addition, the minimum values of temperature decreased. These temperature variations appear to occur as the result of micro-EHD activity which create local modifications in pressure and, hence, viscosity and temperature within the Hertzian contact.

An interesting feature concerning the leading edge of the dent is seen in figure 9(a). While the profile under rolling conditions shows the characteristic reduction in film thickness at the leading edge of the dent, the profile under sliding condition shows less local reduction at this location. The micro-EHD pressure generated by the sliding action associated with the built-up edge of the dent creates an increase in film thickness at this location.

It can generally be stated that the sphere of influence of a dent is much greater under sliding conditions than under rolling conditions. For pure rolling, the local pressures associated with the dent are confined to the inlet region and communicated to the same surface elements on the smooth surface as it passes through the Hertzian region. Howe $\%$ r, under sliding conditions the local pressures generated by the dent are communicated over a larger portion of the smooth surface as the dent sweeps through the Hertzian region.

\section{SINGLE GROOVE - PERPENDICULAR, ROLLING}

The ability to produce grooves in a polished ball was important in that it was then possible to obtain data for defects whose geometry changed in one direction only. These data can be compared to the results obtained in analytical studies of purely transverse and purciy longitudinal stochastic models of roughness in EHD contact as well as results obtained from analytical studies concerned with single two-dimensional asperities in EHD contact. A groove impressed into the surface of a ball with the wedge-shaped tungsten carbide tool leaves a depression which is deepest at its center 
and the depth gradually decreases on both sides of the center along its length as shown in figure 10. However under static Hertzian contact conditions, figure 11 shows that the groove width and deth are essentially constant in the Hertzian region. The groove appears uniform because the elastic deformation gradually decreases from the center of the groove (center of Hertzian circle). The stylus trace of this groove is shown in figure 12 and a comparison between the stylus and static configurations is shown in figure 13. This groove is very shallow measuring only $0.5 \mu \mathrm{m}$ deep which is one-half the depth of the dent discussed above.

A photomicrograph of this groove under rolling conditions is shown in figure 14. Its cross-sectionai profile and static profile are given in figure 15. The general EHD features associated with the groove under rolling conditions are similar to those observed with a dent under rolling conditions A reduction in film thickness is again observed at the leading edge of the defect.

If the static profile is compared with the dynamic profile, as shown in figure 15, it is seen that under the given dynamic conditions the elastic deformation has been substantially relieved from its static condition. This was not observed for the dent discussed above. The difference between the elastic deformations of the groove and dent under dynamic conditions is due to the relative size of these defects with respect to the film thickness; or more precisely, with respect to the size of the inlet region as discussed in reference 20 . If the defect is small and does not significantly modify the shape of the inlet reyion the local hydrodynamic pressura generated in the vicinity of the defect will not be very different from that for smooth surfaces. The defect will then pass through the Hertzian region with less elastic deformation and its shape will approach its undeformed shape as represented by the stylus trace.

$$
\text { SINGLE GROOVE - PERPENDICULAR, SLIDING }
$$

Figure 16(a) and (b) shows a single grnove in two locations within the Hertzian re. gion under sliding conditions. The corresponding cross-sectional profiles are shown in figure 17 (a) and (b). The same general features are observed for the groove under sliding conditions as was seen for the dent under sliding conditions. Sume of these features are not as pronounced for the groove as they were for the dent since the 
groove is smaller than the dent in both depth and width. It is noted from figure 16(a) and (b) that, as with the dent, the groove under sliding conditions shows a pressure "tail" which progressively lags behind the groove as the groove passes through the Hertzian region. A reduction of film thickness is observed within the groove and an increase in film thickness, associated with the converging portion of the built-up edge of the groove, is again seen at the leading edge of the groove under sliding conditions.

To determine the effect of groove geometry on the local EHD pressure modifications, a groove produced with a very sharp tool, as shown in figure 18, was investigated. The stylus trace across the center of the groove is shown in figure 19. The width of this groove $(40 \mu \mathrm{m})$ is the same as the width oi the orvove in figure 12 but its depth $(1 \mu \mathrm{m})$ is twice the depth of the groove shown in figure 12 . The maximum slope of the groove in figure 19 is $5.4^{\circ}$ whereas the maxumum slope of the groove in figure 12 is $2.1^{\circ}$. The deeper groove in figure 19 also has a more substantial built-up edge than the groove in figure 12 .

The deep groove under rolling conditions is shown in figure 20 and its crosssectional profile is shown in figure 21 along with the stylus trace. The interference fringes along the steeply sloped sides of the groove are too close together to be adequately resolved for measurem ent purposes. Only measurements along the edges of the groove could be obtained.

Under rolling conditions an adequate film thickness is seen to occur at the edges of the groove even through the height of the built-up edge $(0.15 \mu \mathrm{m})$ is the same order of magnitude as the nominal film thickness $(0.14 \mu \mathrm{m})$. There $\mathrm{s}$ very little distinction between the leading edge of the groove and the trailing edge as seen previously for the shallow groove and thr dent. Here a local reduction in fllm thlckness occurs on both sides of the groove; but the reduction is only minor compared to the size of the built-up edge. It is evident that a substantial micro-EHD activity can be associated with the built-up edge along the groove. These results are in line with the asperity lubrication discussed by Chow and Cheng (16).

When this deep groove passes through the ilertzian region under sliding conditions additional micro-EHD activity can occur as shown in figure 22 . The cross-sectional profile across the center of the groove is p'otted in figure 23. 
A very substantial film thickness is generated at the leading edge of the groove at the location of the built-up edge. The local converging geometry created by the built-up edge apparently can produce sufficient local EHD presslire that can result in a film thickness at the built-up edge which is larger than the nominal film thicknes:

The trailing edge of the deep groove is distinctly different $\mathrm{f} y \mathrm{~m}$ its leading edge. In addition, the pressure generated at the trailing, edge of the deep groove is different than the pressure generated on the trailing edge ' the shallow groove (fig. 16) and dent (fig. 7) discussed above. The film thickness is very small at the trailing edge of the deep groove and remains small for a significant distance downstream of the groove. However, the trailing edges of the dent and shallow groove, under sliding conditions, showed an increase in film thickness.

The failure of the trailing side of the deep groove to regain the film thickness observed on its leading side is probably the result of the geometry ci groove. The rapidly converging side of the trailing edge of the groove along with the built-up edge and sharp radius of curvature at the shoulder are not purticularly favorable for the local generation of pressure. Consequently, under sliding conditions it is possible to lose the pressure within the groove and not regain it back on the trailing side if the geometric features on the trailing side are not favorable for pressure generation.

Perhaps the most distinctive feature of figure 22 is a localized region which does not show elther the reduction in film thickness at the trailing edge of the groove or the slight increase in film thickness at the leading edge of the groove. The film thickness profile in this region is plotted in figure 24 and a stylus trace across this portion of the groove is shown in figure 25 . When compared with figure 19 it can be seen that this portion of the groove does not show a significant built-up edge; and, the shoulders of the groove are much more rounded. (While it is not known buw this portion of the groove gct this way, the effect of "run-in" may show a similar modification.) The depth at these two portions of the groove is approximately the same. These results emphasize the Importance of the slope or curvature nf the surfuce topography that comes within close proximity of the opposing bearing surfuces. The topography is intimately involved w th the lubrication process iter'f. 


\section{SINGLE GROOVE - PARALLEL}

Many bearing surfaces have grinding furrows which are parallel to the direction of motion (2). The groove shown in figure 26 was made on the ball surface in an orientation parallel to the direction of f'ow. The stylus trace across the groove is shown in figure 27. The groove is approximately $35 \mu \mathrm{m}$ wide and $0.55 \mu \mathrm{m}$ deep. A substantial built-up adge $(0.25 \mu \mathrm{m})$ is present on one side. On the other side the b'ilt-up edge is relatively small.

The parallel groove under rolling conditions is shown in figure 28 , the crosssectional profile along with the stylus trace are plotted in figure 29 . The superposition of the stylus trace on the dynamic profile shows a reduction in film thickness on the side of the groove that does not have a built-up edge. This reduction in film thickness is similar to that found at the ends of rollers for line contact geometries $(23,32)$. The reduction in film thickness is very localized and is due to the side-leakage that occurs as the groove passes through the inlet region.

The other side of the groove shows surface separation over most of the region of the built-up edge. A small portion of this region is at a fringe order below the first fringe (black). The first fringe occurs at a film thickness of $0.05 \mu \mathrm{m}(2 \mu \mathrm{in}$.$) .$

Figure 26 shows no significant surface damage to the edge of the groove even after considerable operation under both rolling and sliding conditions.

The groove under sliding conditions is shown in figure 30 and its cross-sectional profile is plotted in figure 31 . The film thickness distribution for rolling (fig. 29) and sliding (fig. 31) are almost identical. This is contrary to what was observed when the groove was oriented perpendicular to the direction of flow where substantial differences were observed between rolling and sliding conditions. For the case when the groove is oriented in the direction of flow, there is comparatively little change in the geometry of the groove in this direction as it passes through the Hertzian region so that the presence of sliding will not significantly alter the micro-EHD activity. Thus, for topographical features oriented in the direction of flow the micro-EHD action is confined to the inlet region for sliding as well as for rolling conditions. 


\section{DISCUSSION}

It has been shown that it is possible to artificially produce surface defects, characterized as dents and grooves, on bearing surfaces. The dents are remarkably similar to the debris dents found on bearing surfaces which are known to be vulnerable sites for surface initiated fatigue. It has been shown (25) that very substantial stress concentrations occur at the shoulders of these defects.

The local film thickness measurements presented here for the artificially produced dent under pure rolling conditions substantiate the general observations of reference 20 . These observations imply that the mechanism of EHD lubrication (on both a micro and macro scale) can substantially influence the stress concentrations in the vicinity of the dent. When the characteristic film thickness becomes large relative to the characteristic dent dimensions, the stress concentrations are relieved. It was found that the local EHD pressure variations around the dent as it passed through the Hertzian region was the result of a modification of the inlet pressure distribution caused by the dent geometry as it passes through the inlet region. The shape of the inlet region is important for

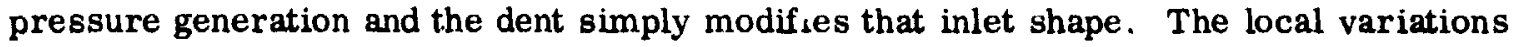
of the geometry of the inlet region explains why the film thickness at the leading edge of the dent was found to be much lower than the trailing edge. This leads to the interesting conclusion that the stress concentration will be greater at the trailing edge than the leading edge, which agrees with the observations of surface initiated fatigue found in practice.

The results presented here for the dent under sliding conditions introduces additional micro-EHD features. Under sliding conditions, the film thickness variation, and thus pressure variation, in the vicinity of the dent is more pronounced than under pure rolling conditions. In addition, under pure sliding conditions, high pressures and thus high stress concentrations lagging the dent were observed. These high pressures result from micro-EHD effects caused by the favorable pressure-generating geometry at the trailing edge of the dent as it passes through the Hertzian region.

The pure rolling results obtained for grooves perpendicular and parallel to the direction of flow indicate that both types of grooves reduced the nominal film thickness 
when compared to a smooth surface. However, perpendicular grooves reduced this nominal film thickness to a lesser degree than parallel grooves. Under pure sliding conditions, micro-EHD effects were much more dominant around grooves which were oriented perpendicular to the direction of flow than around grooves which were oriented parallel to the direction of flow.

As indicated above, the artificially-produced defects and their associated built-up edges have a substantial effect on the film thickness variations in the vicinity of the defect especially under pure sliding conditione. In practice, similar defects and builtup edges can be expected from debris dents and manufacturing scratches and, thus, similar pressure variations are likely to occur if these defects exist in mechanical elements which are subjected to EHD lubrication conditions. 'The observed film thickness variation suggests that metal-to-metal contact can take place where there is a reduction of film thickness and very high stress concentrations can be generated where there is an increase in film thickness.

These micro-EHD events are very real and measurable. They further indicate that whenever lubricated surfaces approach each other, particularly under sliding EHD conditions, we can expect the following: first, the topography of the surfaces become intimacely involved in the lubrication process itself; and second, the surfac opography, as it passes through the Hertzian region, can be significantly modified as the result of micro-EHD events. There appears to be a much greater world of activity on a micro-EHD scale than the simple film thickness to surface roughness ratio $(h / \sigma)$ would seem to indicate. This realm of activity must be penetrated before the traditional boundary lubrication regime is ever reached.

\section{CONCLUSIONS}

In addition to the conclusions enumerated under SINGLE DENT-ROLLING, the following observations can be made about dents and grooves under dynamic conditions:

1. Micro-EHD effects cause a substantial increase in fllm thickness and thus stress concentrations behind both grooves which are oriented perpendicular to the direction of flow and dents as these defects pass through the Hertzian contact area under pure sliding conditions. 
2. Under pure rolling conditions, the nominal film thickness observed for grooves oriented in a direction parallel to the flow and perpendicular to the flow is smaller than film thickness observed for smooth surfaces operating under the same conditions. Grooves oriented perpendicular to the direction of flow, however, seem to reduce this nominal film thickness to a lesser degree than grooves oriented parallel to the direction of flow.

3. It can generally be stated that dents and grooves affect the film thickness distribution in the contact area more when the surfaces are under pure sliding than when they are under pure rolling.

4. The slope of the defects and the built-up edge around the defects can have significant effects on the micro-EHD action in the vicinity of the defects.

5. Oil-film thickness variations are generally localized in the vicinity of the defects.

6. The presence of sliding for a groove oriented parallel to the direction of flow will not significantly alter the film thickness observed under pure rolling conditions; thus, micro-EHD effects are confined to the inlet region for both sliding and rolling conditions.

7. These results experimentally support the concept that as lubricated surfaces approach each other, particularly under sliding conditions, the surface topography become intimately involved in the lubrication process itself; and by so doing, greatly modifies the surface topography as it passes through the Hertzian region.

\section{ACKNOW LEDGMENT}

The authors would like to thank Tom Morrell who meticulously measured the dent profiles and plotted the dent shapes from the interference fringes. 


\section{REFERENCES}

(1) Tallian, T. E. and McCool, J. I., "An Engineering Model of Spalling Fatigue in Rolling Contact - The Surface Model," Wear, 17, 447-461 (1971).

(2) Tallian, T. E., "The Theory of Partial Elastohydrodynamic Contacts," Wear, 21, 49-101 (1972).

(3) Li, D. F., Kauzlarich, J. J., and Jamison, W. E., "Surface Roughness Effects on Fatigue in Partial EHD Lubrication," J. Lubr. Technol., ASME Trans., 98, Series F (4), 530-537 (1976).

(4) Loewenthal, S. H. and Moyer, D. W., "Filtration Effects on Ball Bearing Life and Condition in a Contaminated Lubricant." NASA TM-78907, 1978.

(5) Tzeng, S. T. and Saibel, E., "Surface Roughness Effects on Slider Lubrication," ASLE Trans. , 10, 334-338 (1967).

(6) Christensen, H., "Stochastic Models for Hydrodynamic Lubrication of Rough Surfaces," Proc. Inst. Mech. Eng., 184, Pt. 1 (55), 1013-1022 (1969-1970).

(7) Christensen, H., "A Theory of Mixed Lubrication," Proc. Inst. Mech. Eng., $186,41,421-430(1972)$.

(8) Christensen, H. and Tonder, K., "The Hydrodynamic Lubrication of Rough Bearing Surfaces ff Finite Width," J. Lubr. Technol., ASME Trans., 93, Series F (3), 324-330 (1971).

(9) Christensen, H. and Tonder, K., "I'he Hydrodynamic Lubrication of Rough Journal Bearings," J. Lubr. Technol., ASME Trans., 95, Series F (2), 166-172 (1973).

(10) Tonder, K. and Christensen, H., 'Waviness and Roughness in Hydrodynamic Lubrication, " _zoc. Inst. Mech. Eng., 186 (72/72), 807-812 (1972).

(11) Tonder, $K$, "Lubrication of Surfaces Having Area-Distributed Isotropic Roughness " J. Lubr. Technol. ASME Trans. , 99, Series F (3), 323-330 (1977).

(12) Surn, D. and Chen, K., "First Effects of Stokes Roughness on Hydrodynamic Lubrication," J. Lubr. Technol., ASME Trans., 99, Series F (1), 2-9 (1977).

(13) Rhow, S. K. a.dd Elrod, H. G., "The Effects on Bearing Load-Carrying Capacity of Two-S ded Striated Roughness," J. Lubr. Technol. ASME Trans., 96, Seriar. F (4) 554-560 (1974). 
(14) Chow, L. S. H. and Cheng, H. S., "The Effect of Surface Roughness on the Average Film Thickness Between Lubricated Rollers," I. Lubr. Technol., ASME Trans., 98, Series F (1), 117-124 (1976).

(15) Johnson, K. L., Greenwood, J. A., and Poon, S. Y., "Simple Theory of Asperity Contact in Elastohydrodynamic Lubrication," Wear, 19, 91-108 (1972).

(16) Chow, L. S. H. and Cheng, H. S., "Pressure Perturbation in EHD Contacts Due to an Ellipsoidal Asperity," J. Lubr. Technol., ASME Trans., 98, Series F (1), 8-15 (1976).

(17) Fowles, P. E., "The Application of Elastohydrodynamic Lubrication Theory to Individual Asperity-Aspe :ity Collisions," J. Lubr. Technol. ASME Trans., 91, Series F (3), 464-476 (1969).

(18) Fowles, P. E., "Extension of the Elastohydrodynamic Theory of Individual Asperity-Asperity Collisions to the Second Half of the Collision," J. Lubr. Technol., ASME Trans., 93, Series F (2), 213-215 (1971).

(19) Jackson, A. and Cameron, A., "An Interferometric Study of the EHL of Rough Surfaces," ASLE Trans., 19 (1), 50-60 (1976).

(20) Wedeven, L. D., "Influence of Debris Dent on EHD Lubrication," ASLE Trans., 21 (1), 41-52 (1978).

(21) Wedeven, L. D., "Traction and Film Thickness Measurements Under Starved Elastohydrodynamic Conditions," J. Lubr. Technol., ASME Trans., 97, Series F (2), 321-329 (1975).

(22) Wedeven, L. D., "Effect of Starvation on Film Thickness and Traction Under Elastohydrodynamic Rolling and Sliding Conditions," NASA TN D-8087, 1975.

(23) Wedeven, L. D., Evans, D., and Cameron, A., 'Optical Analysis of Ball Bearing Starvation," J. Lubr. Technol., ASME Trans., 93, Series F (3), 349-363 (1971).

(24) Foord, C. A., Wedeven, L. D., Westlake, F. J., and Cameron, A., 'Optical Elastohydrodynamics," Proc. Inst. Mech. Eng., 184, pt. 1 (28), 487-505 (1969-1970).

(25) Littmann, W. E. and Widner, R. L., "Propagation of Contact Fatigue from Surface and Subsurface Origins," ASME Trans., J. Basic Eng., 88, 624-636 (1966). 
(26) Chiu, Y. P. and Liu, J. Y., "An Analytical Study of the Stress Concentration Around a Furrow Shaped Surface Defect in Rolling Contact," J. Lubr. Technol., ASME Trans., 92, Series F (2), 258-263 (1970).

(27) Parker, R. J., "Correlation of Magnetic Perturbation Inspection Data with Rolling Element Bearing Fatigue Results," ASME Trans., J. Lubr. Technol., 97, Series F (2), 151-158 (1975).

(28) Rumbarger, J. H. and Leonard, L., "Derivation of a Fatigue Life Model for Gears," USAAMRDL Technical Report 72-14, May 1972. AD-744504

(29) Lee, K. and Cheng, H. S., "Effect of Surface Asperity on Elastohydrodynamic Lubrication," NASA CR-2195, 1973. (See also discussion to ref. 19.)

(30) Tallian, T. E., "Pressure and Traction Rippling in Elastohydrodynamic Contact of Rough Surfaces," ASME Trans., J. Lubr. Technol., 96, Series F (3), 398409 (1974).

(31) Winer, W. O. and Sanborn, D. M., "Lubricant Rheology Applied to Elastohydrodynamic Lubrication," NASA CR-2837, 1977.

(32) Wymer, D. G. and Cameron, A., "Elastohydrodynamic Lubrication of a Line Contact," Proc. Inst. Mech. Eng., 188 (19/74), 221-238 (1974). 
TABLE I. - BEARING MATERLAL PROPERTIES

\begin{tabular}{|l|r|r|}
\hline & \multicolumn{1}{|c|}{ Ball } & \multicolumn{1}{c|}{ Disk } \\
\hline Material & 52100 Steel & Sapphire \\
Compressive strength & $1.4 \times 10^{9} \mathrm{~N} / \mathrm{m}^{2}$ & $2 \times 10^{9} \mathrm{~N} / \mathrm{m}^{2}$ \\
Elastic modulus & $204 \times 10^{9} \mathrm{~N} / \mathrm{m}^{2}$ & $365 \times 10^{9} \mathrm{~N} / \mathrm{m}^{2}$ \\
Poisson's ratio & 0.3 & 0.25 \\
Hardness & $65 \mathrm{R}$ & 9 Moh \\
Roughness & $0.08 \mu \mathrm{m} \mathrm{rms}$ & Optical polish \\
\hline
\end{tabular}

TABLE II. - PROPERTIES OF TEST FLUID

\begin{tabular}{|l|r|}
\hline & Synthetic paraffinic oil (XRM 109F3) \\
\hline Viscosity & $45830 \mathrm{cS}$ at $17.8^{\circ} \mathrm{C}$ \\
& $493 \mathrm{cS}$ at $37.8^{\circ} \mathrm{C}$ \\
Density & $42.6 \mathrm{cS}$ at $98.9^{\circ} \mathrm{C}$ \\
& $0.8389 \mathrm{~g} / \mathrm{cm}^{3}$ at $37.8^{\circ} \mathrm{C}$ \\
& $0.8082 \mathrm{~g} / \mathrm{cm}^{3}$ at $93.3^{\circ} \mathrm{C}$ \\
& $0.777 \mathrm{~g} / \mathrm{cm}^{3}$ at $149^{\circ} \mathrm{C}$ \\
Pressure & $1.77 \times 10^{-8} \mathrm{~m}^{2} / \mathrm{N}$ at $37.8^{\circ} \mathrm{C}$ \\
viscosity & $1.51 \times 10^{-8} \mathrm{~m}^{2} / \mathrm{N}$ at $99^{\circ} \mathrm{C}$ \\
coefficient & $1.09 \times 10^{-8} \mathrm{~m}^{2} / \mathrm{N}$ at $149^{\circ} \mathrm{C}$ \\
Refractive index & 1.4689 at $23^{\circ} \mathrm{C}$ \\
\hline
\end{tabular}




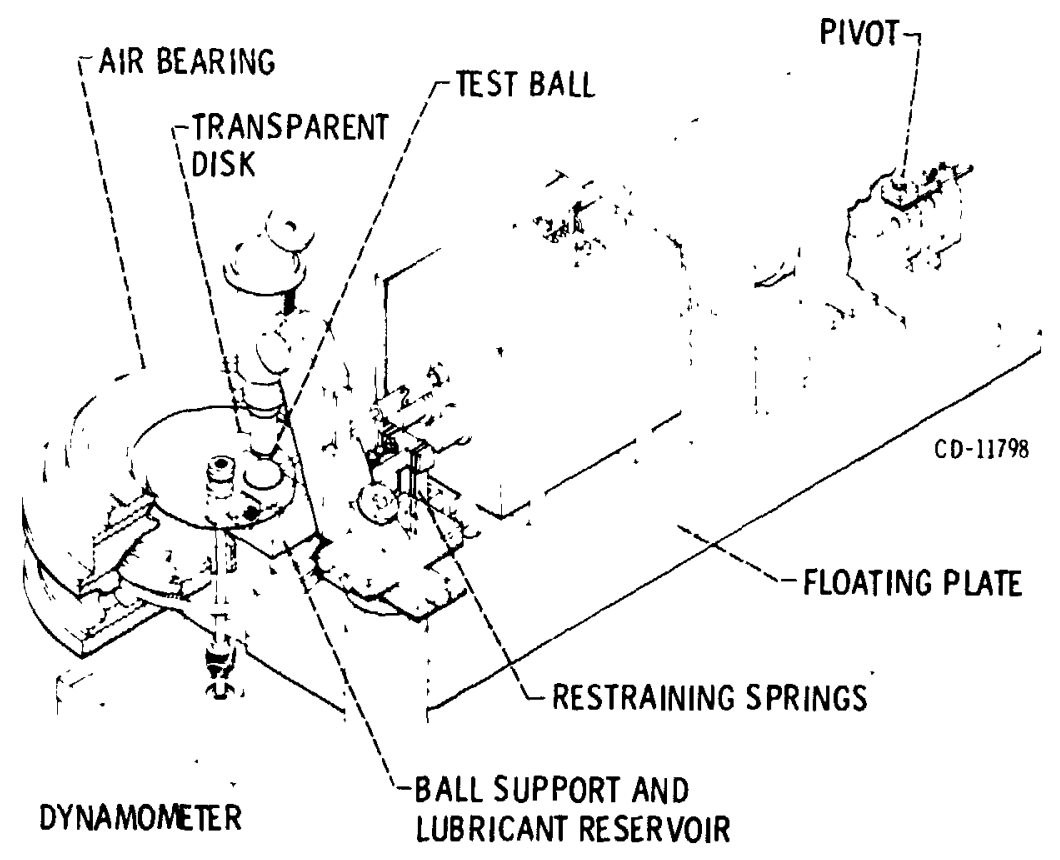

Figure 1. - Optical EHD rig.

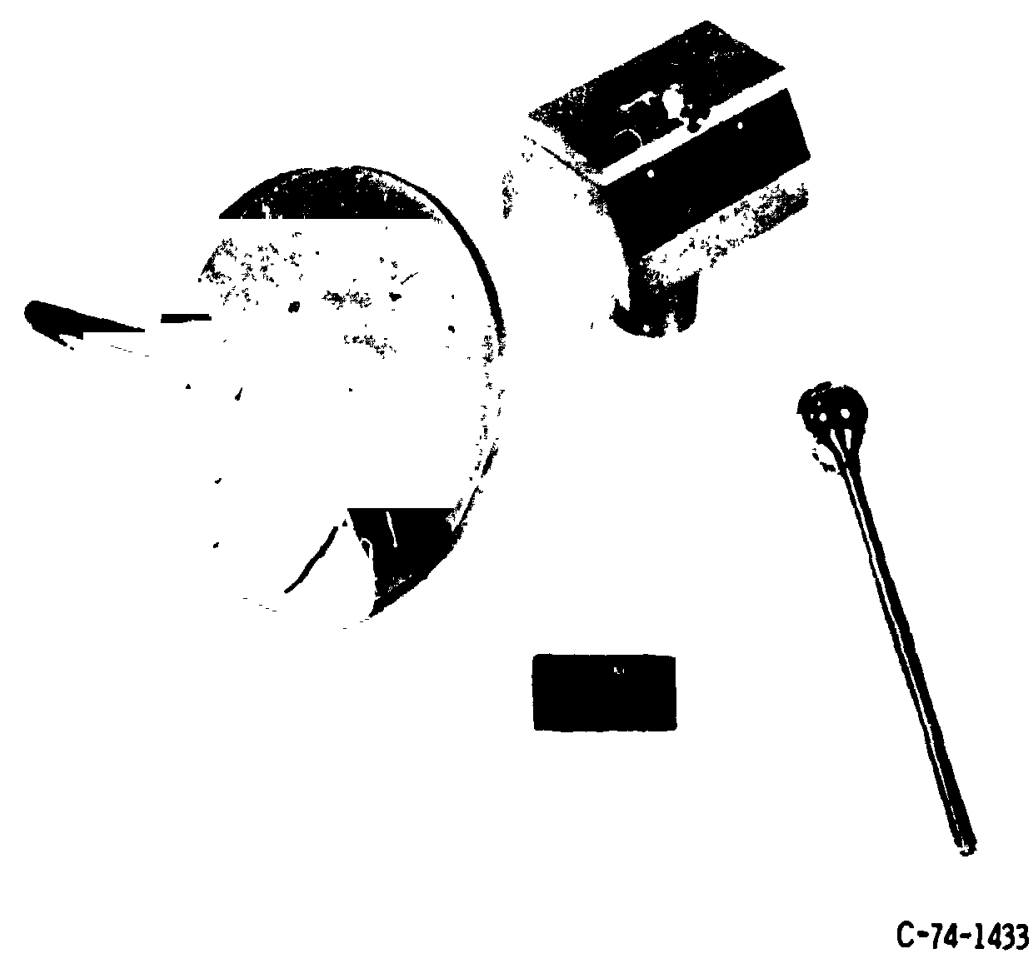

Figure 2. - Test ball, transparent disk and lubricant reservoi r. 


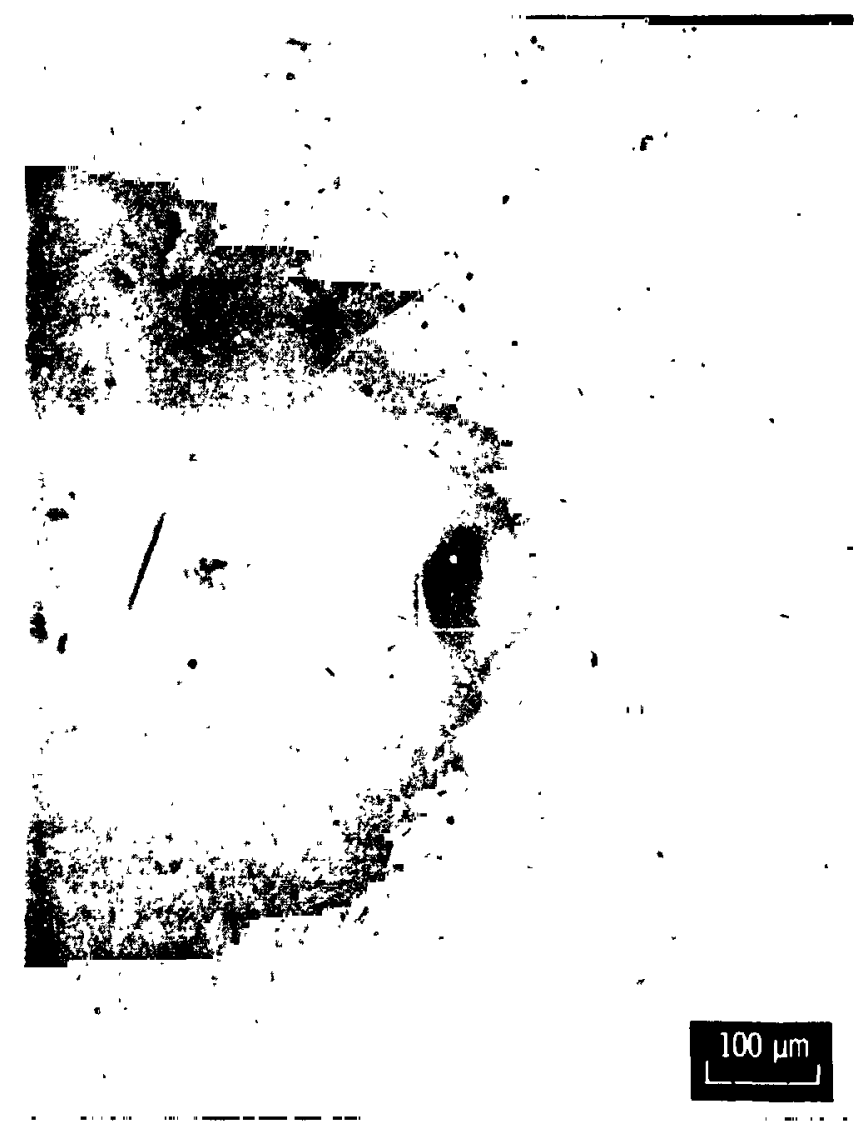

Figure 3. - Dent made with conical tool and $44.5 \mathrm{~N}$ load.

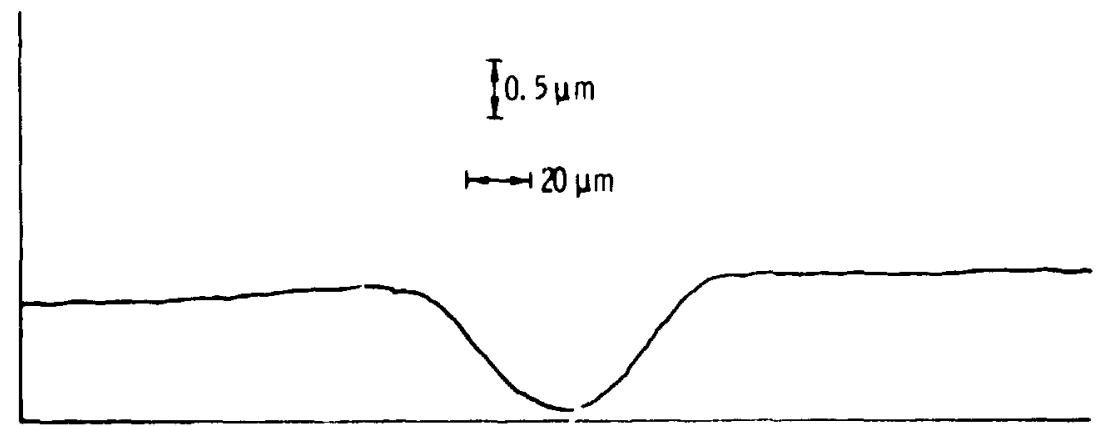

Figure 4. - Stylus trace of dent shown in figure 3. 


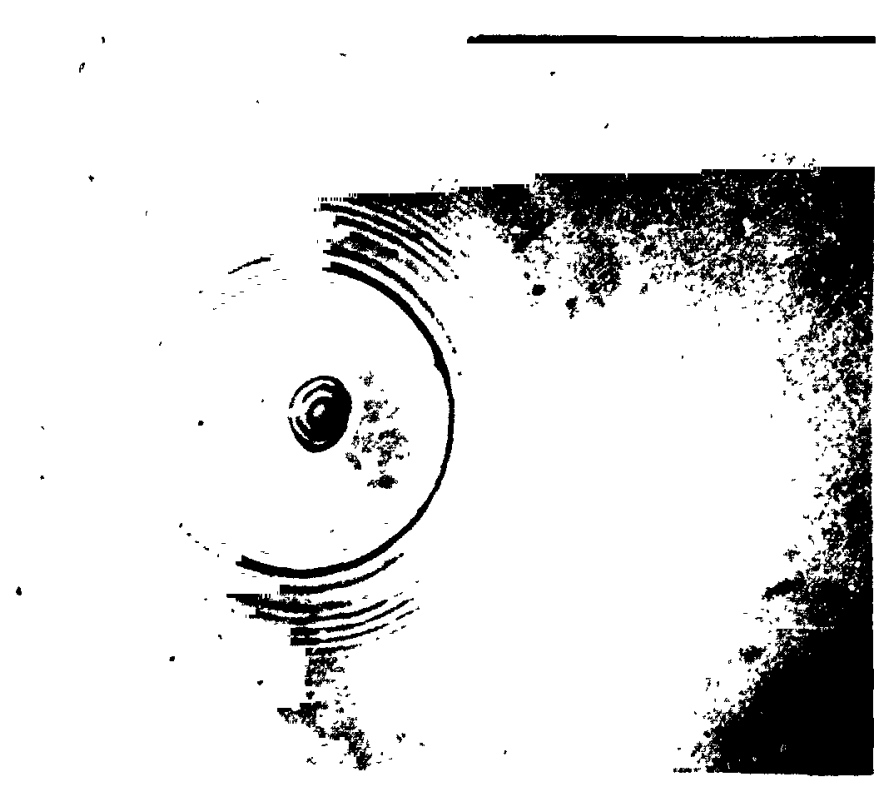

Figure 5. - Photomicrograph of dent in static contact; $P_{\max }=1.13 \times 10^{9}$ $N / M^{2}$.

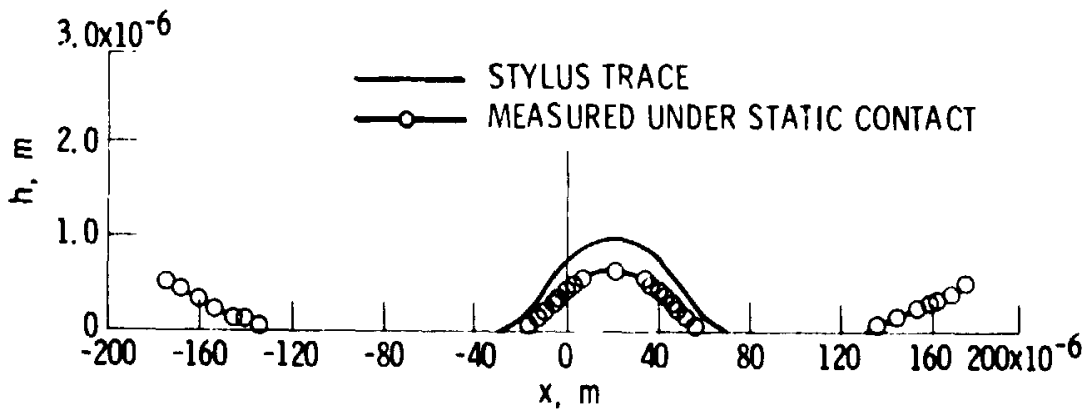

Figure 6. - Comparison of undeformed dent profile (stylus trace) with measured profile under static conlact. 


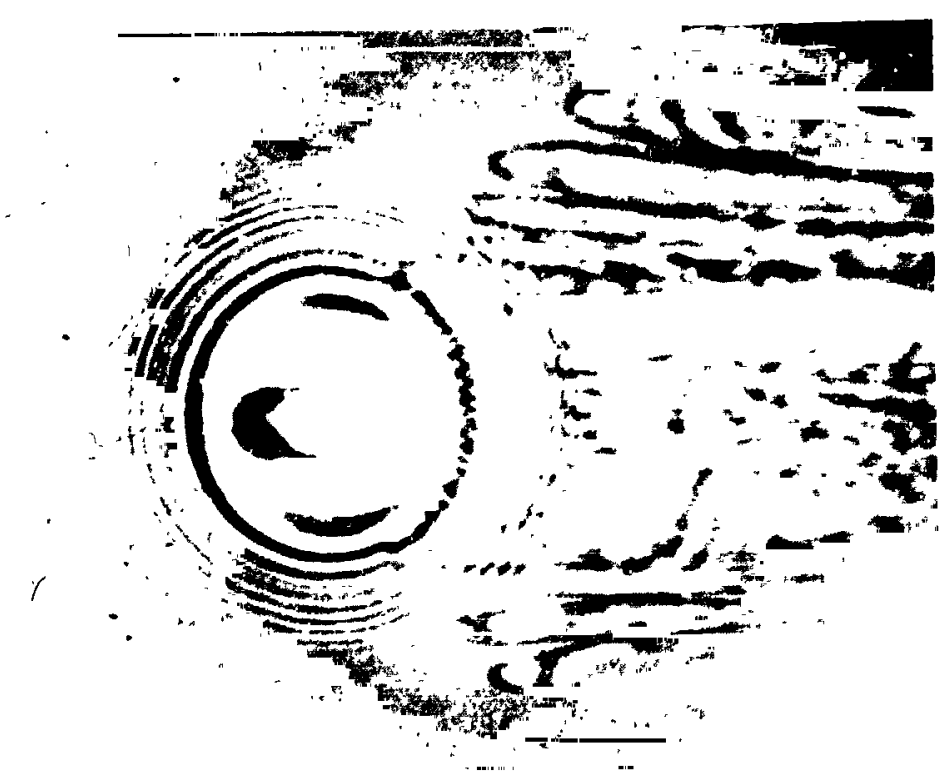

Figure 7(a). - Photomicrograph of dent under sliding conditiors; dent in center. $U=0.0134 \mathrm{M} / \mathrm{S}, \mathrm{P}_{\max }=1.13 \times 10^{9} \mathrm{~N} / \mathrm{M}^{2}$.

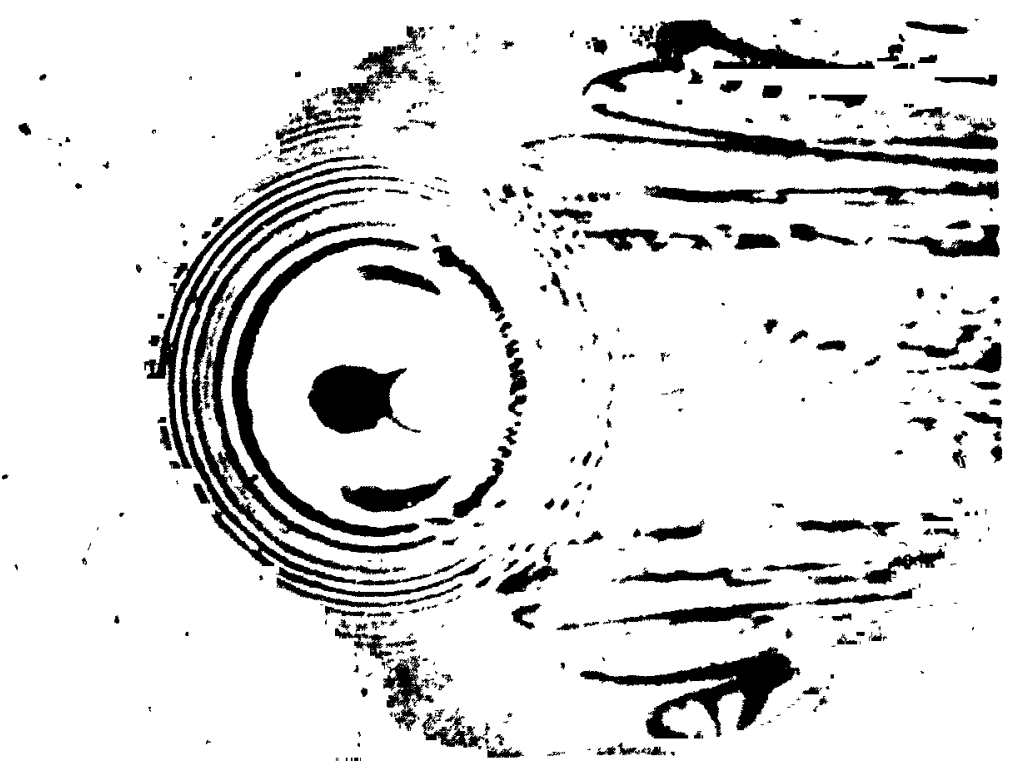

Figure $7(b)$. - Photomicrograph of dent under sliding conditions; dent near rear of Hertzian region. $U=0.0134 \mathrm{M} / \mathrm{S}, P_{\max }=1.13 \times 10^{9} \mathrm{~N} / \mathrm{M}^{2}$. 


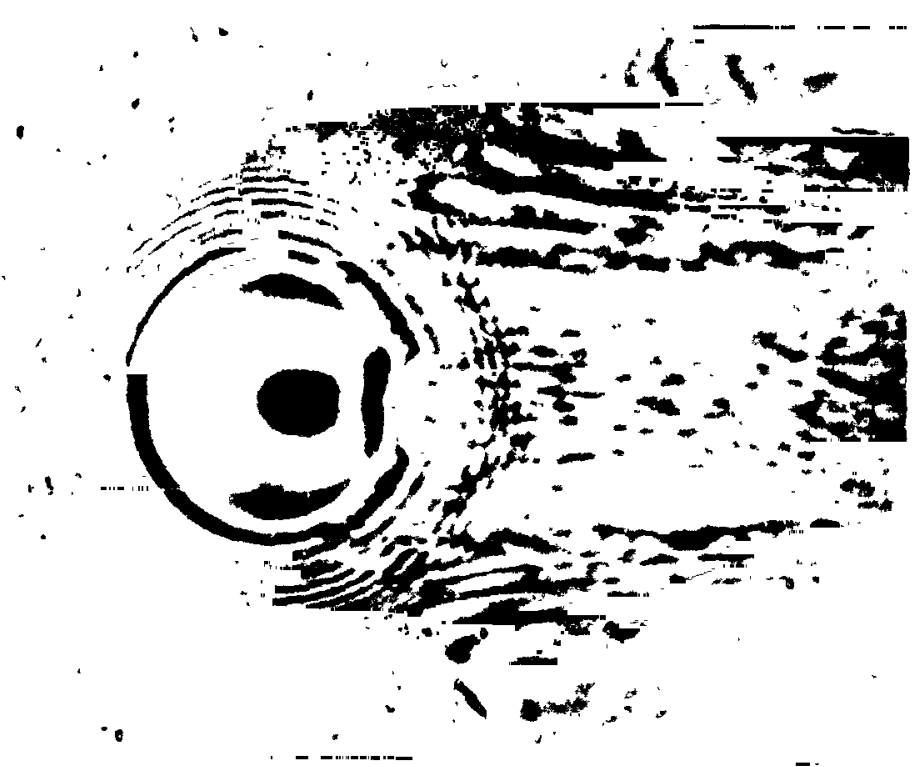

Figure $7(c)$. - Photomicrograph of dent under sliding conditions; dent in exit rogion. $U=0.0134 \mathrm{M} / \mathrm{S}, P_{\max }=1.13 \times 10^{4} \mathrm{~N} / \mathrm{M}^{2}$.

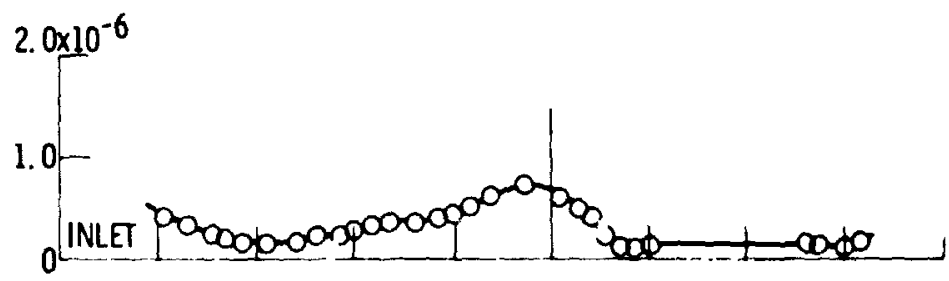

(a) MEASURED PROFILE OF FIG. 7ia).

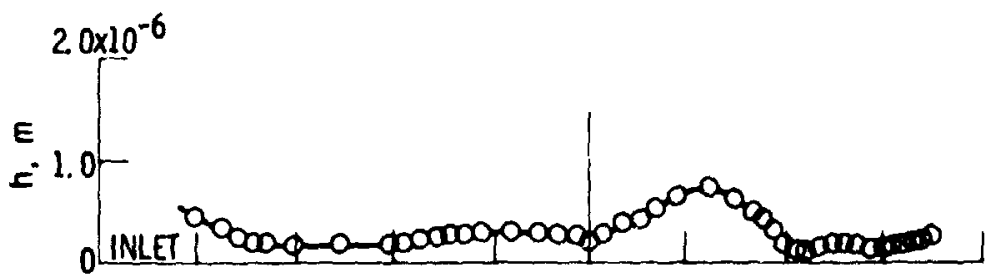

(b) MEASURED PROFILE OF FIG. 7(b).

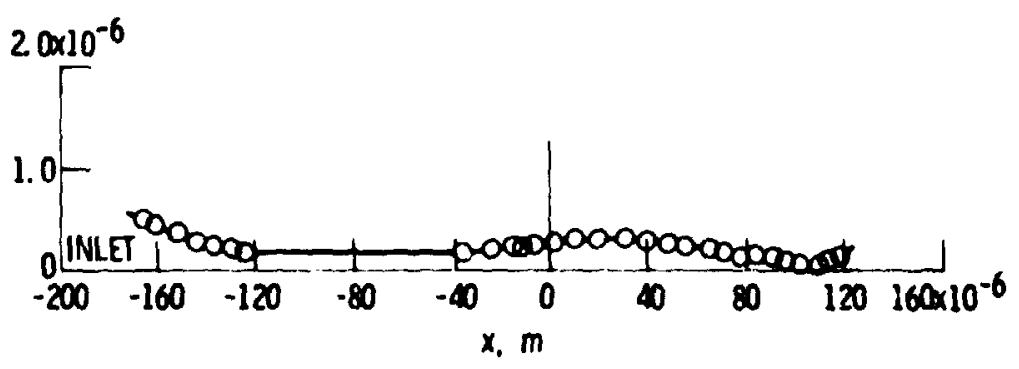

(c) MEASURED PROFII.E OF FIG. 7IC).

Figure 8. 


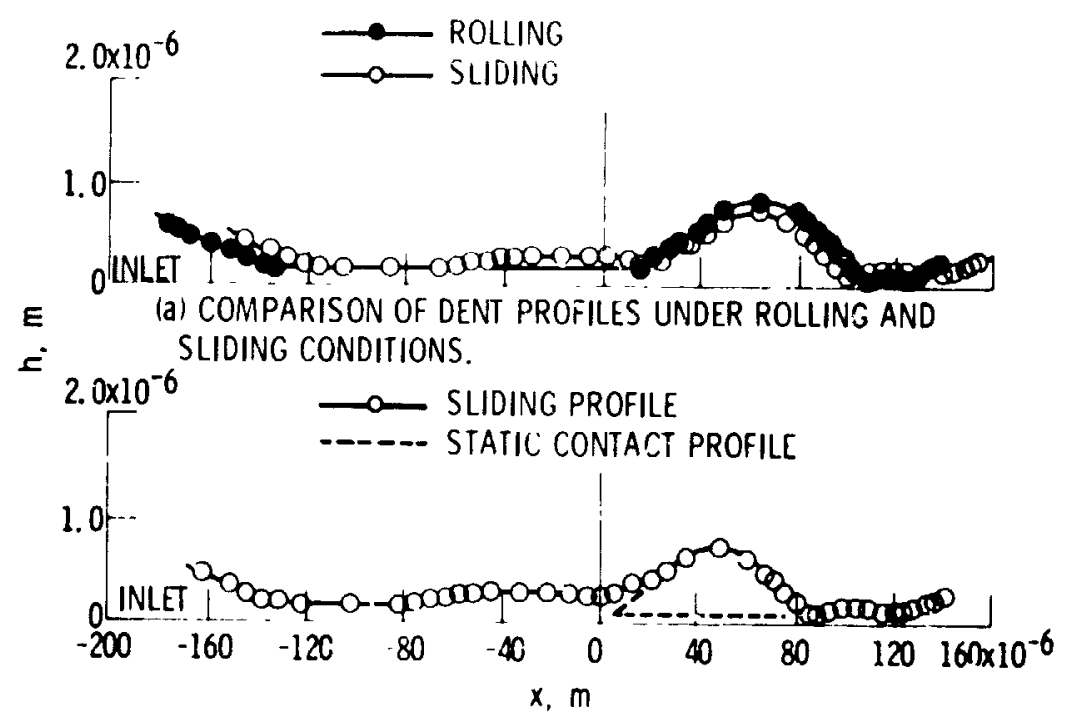

(b) COMPARISON OF SLIDING PROFILE WITH STATIC CONIACT PROFILE.

Figure 9.

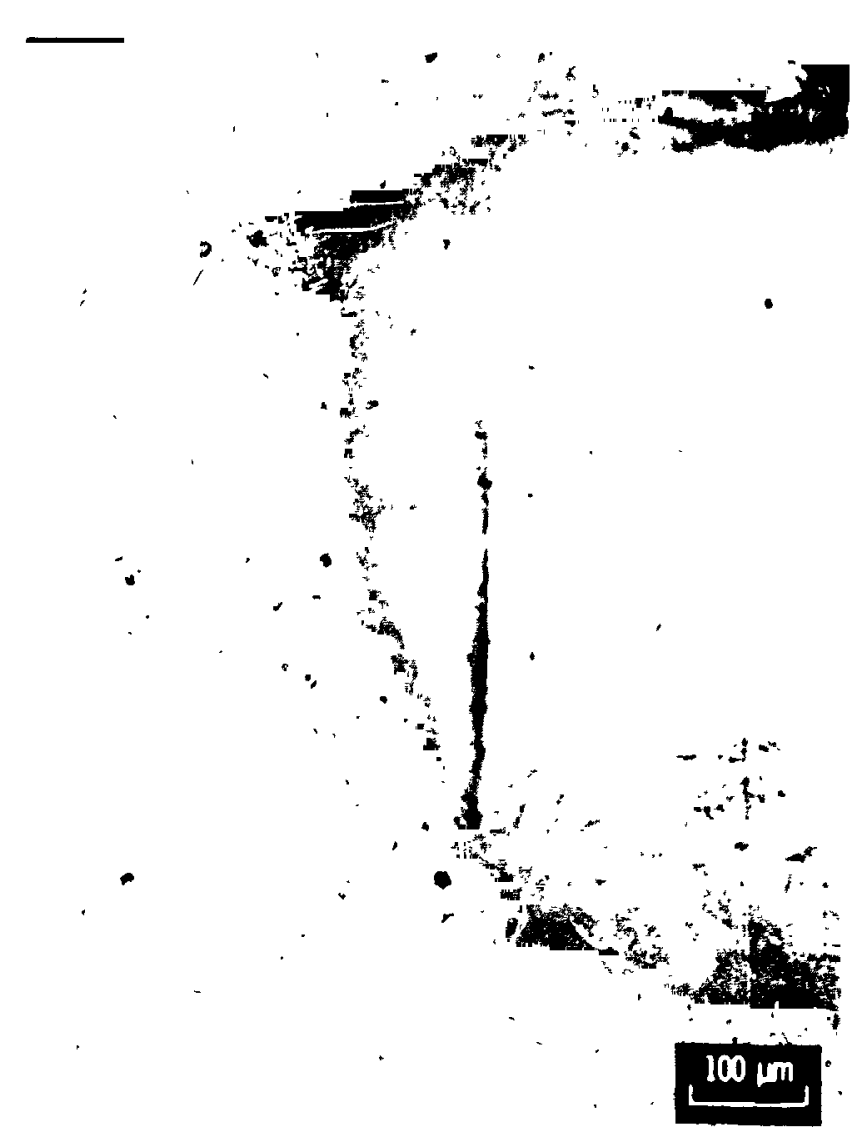

Figure 10. - Shallow groove made with wedge-shaped tool. 


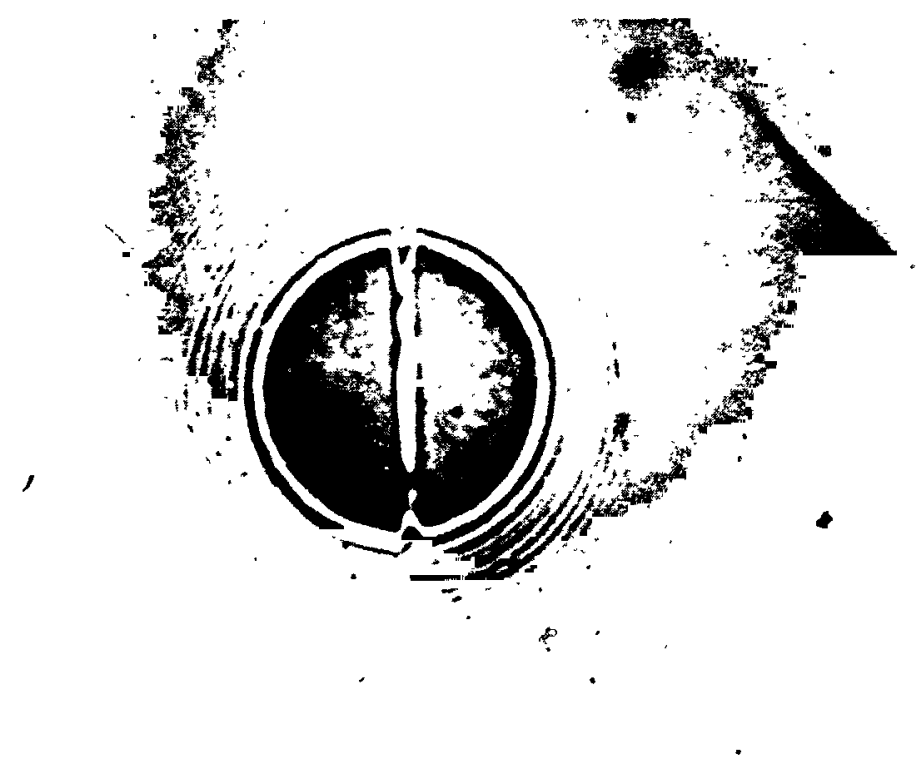

Figure 11. - Shallow groove in static contact. $P_{\max }=1.13 \times 10^{9} \mathrm{~N} / \mathrm{M}^{2}$.

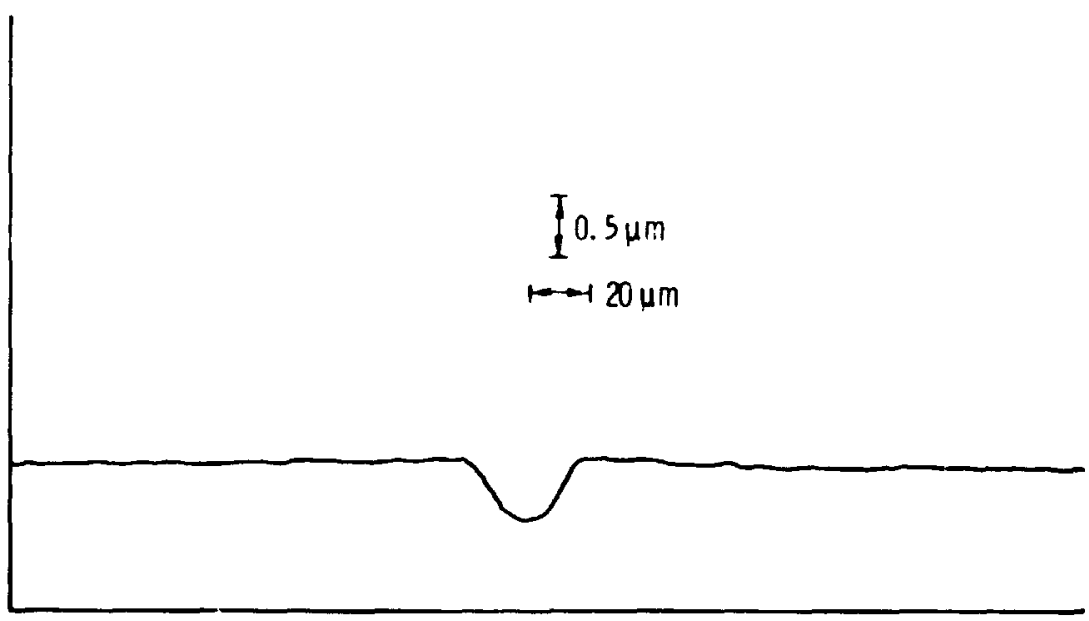

Figure 12. - Stylus trace of shallow groove in figure 10. 


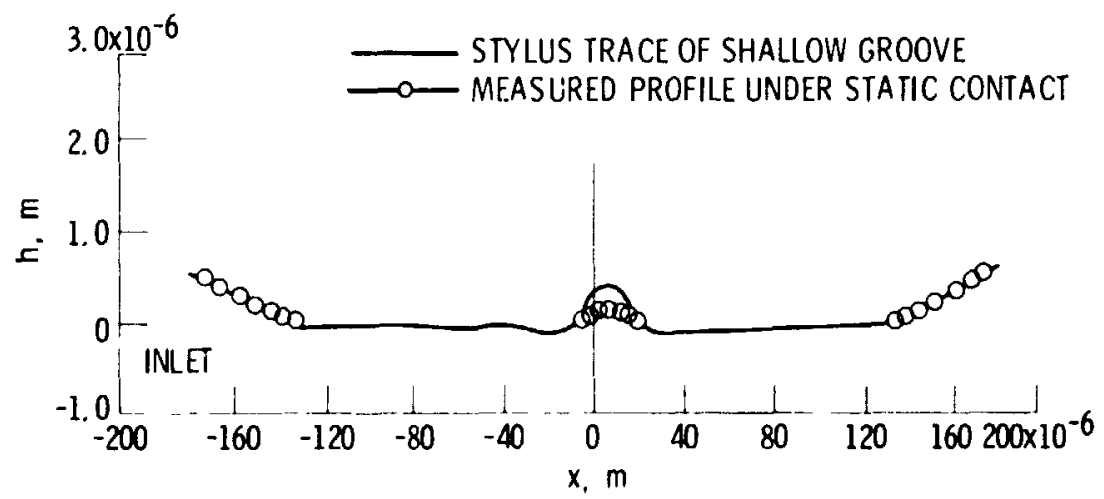

Figure 13. - Comparison of stylus trace of shallow groov, with groove profile under static conditions.

\footnotetext{
m
}

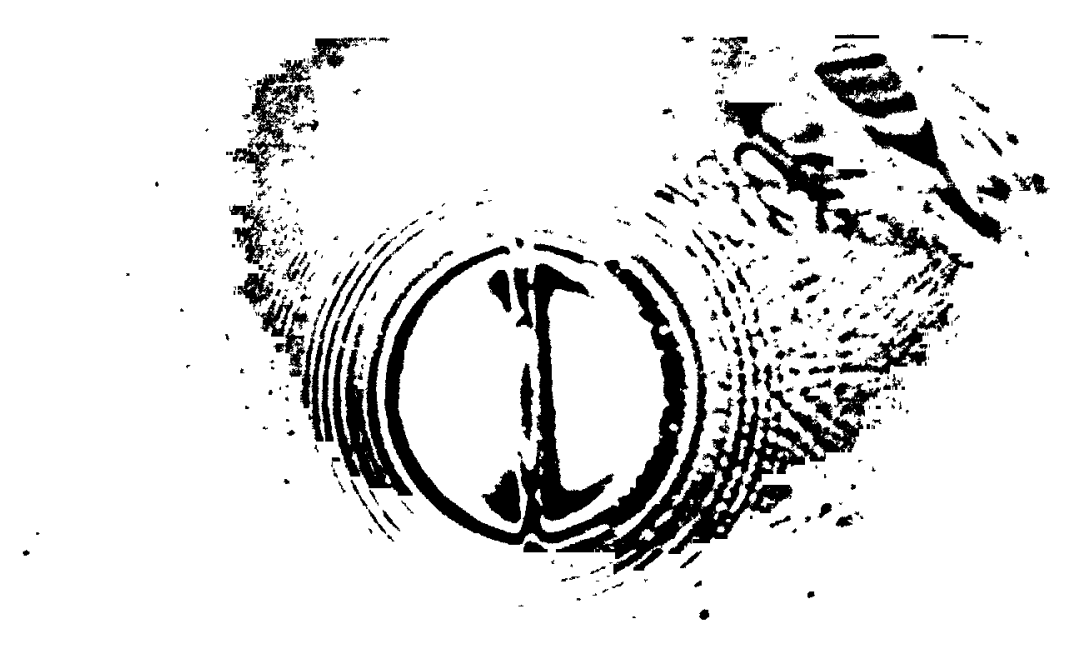

Figure 14. - Shallow groove under rolling conditions, $\mathrm{U} \cdot 0.0134 \mathrm{M} / \mathrm{S}$, $P_{\max }=1.13 \times 10^{9} \mathrm{~N} / \mathrm{M}^{2}$. 


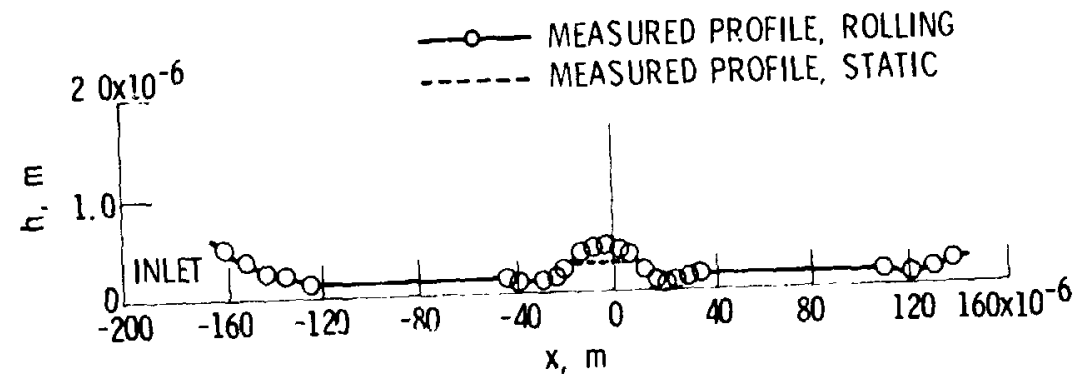

Figure 15. - Comparison of static profile with dynamic profile under rolling conditions.

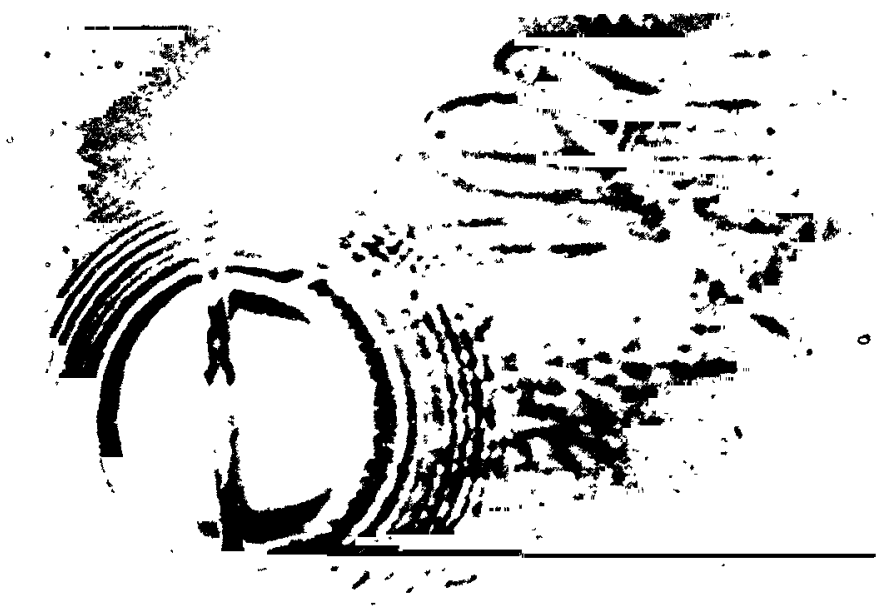

Figure 16ial. - Photomicrograph of groove in sliding; groove in center of Hertzian region. $U=0.0134 \mathrm{M} / \mathrm{S}, P_{\max }=1.13 \times 10^{9} \mathrm{~N}^{\mathrm{M}}{ }^{2}$. 


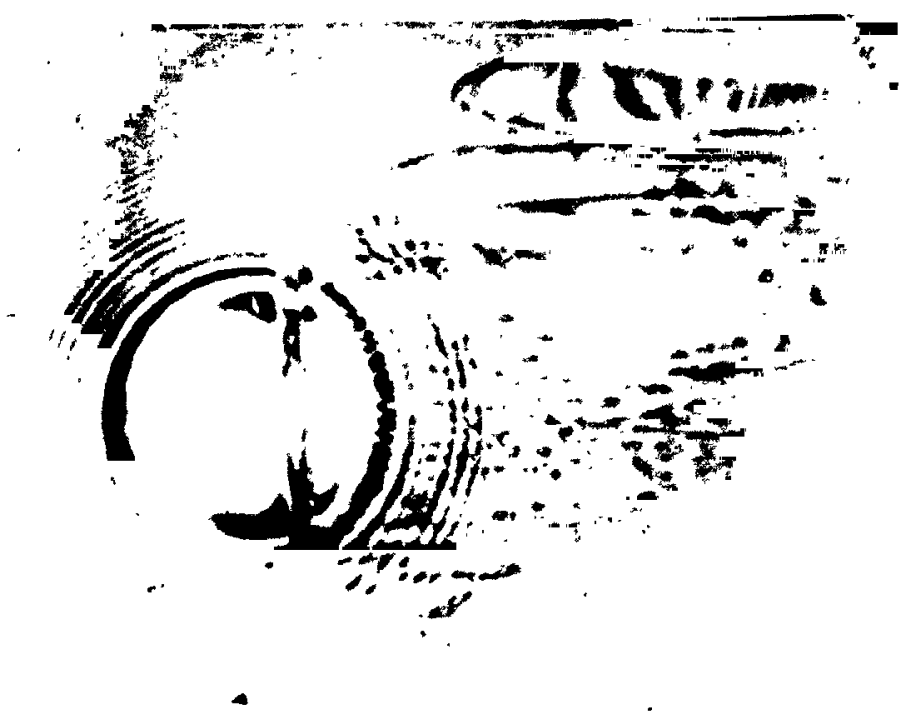

Figure 16(b). - Photomicrograph of groove in sliding; groove near rear of Hertzian region. $U \cdot 0.0134 \mathrm{M} / \mathrm{S}, \mathrm{P}_{\max }=1.13 \times 10^{9} \mathrm{~N} / \mathrm{M}^{2}$.

?

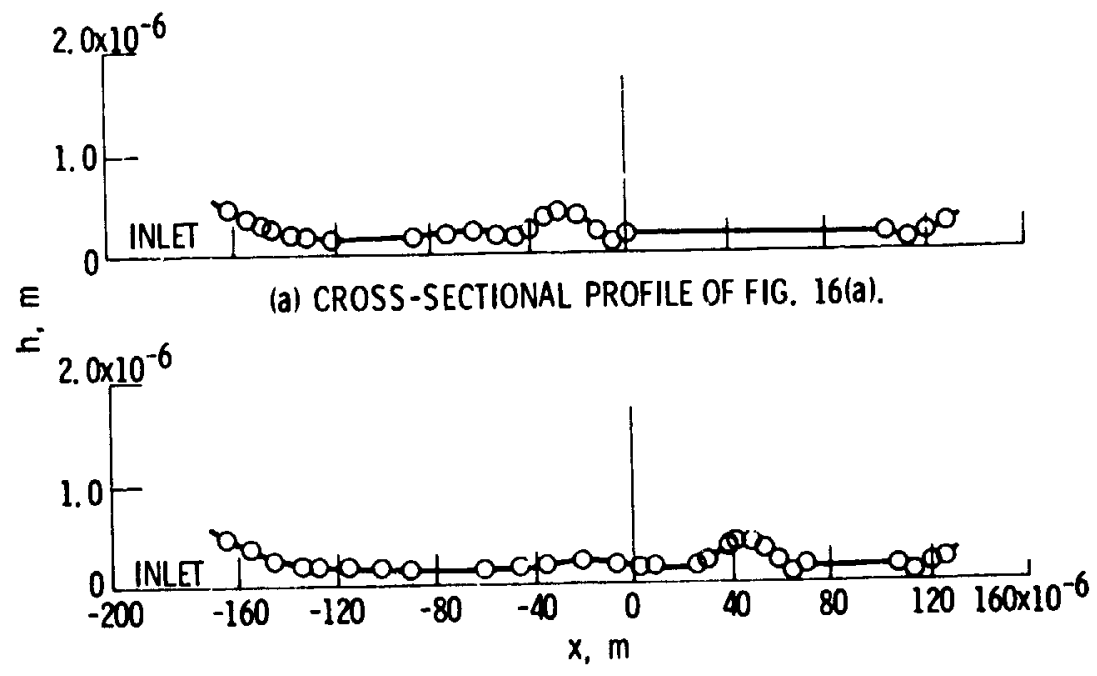

(b) CROSS-SECTIONAL PROFILE OF FIG. 16(b).

Figure 17. 


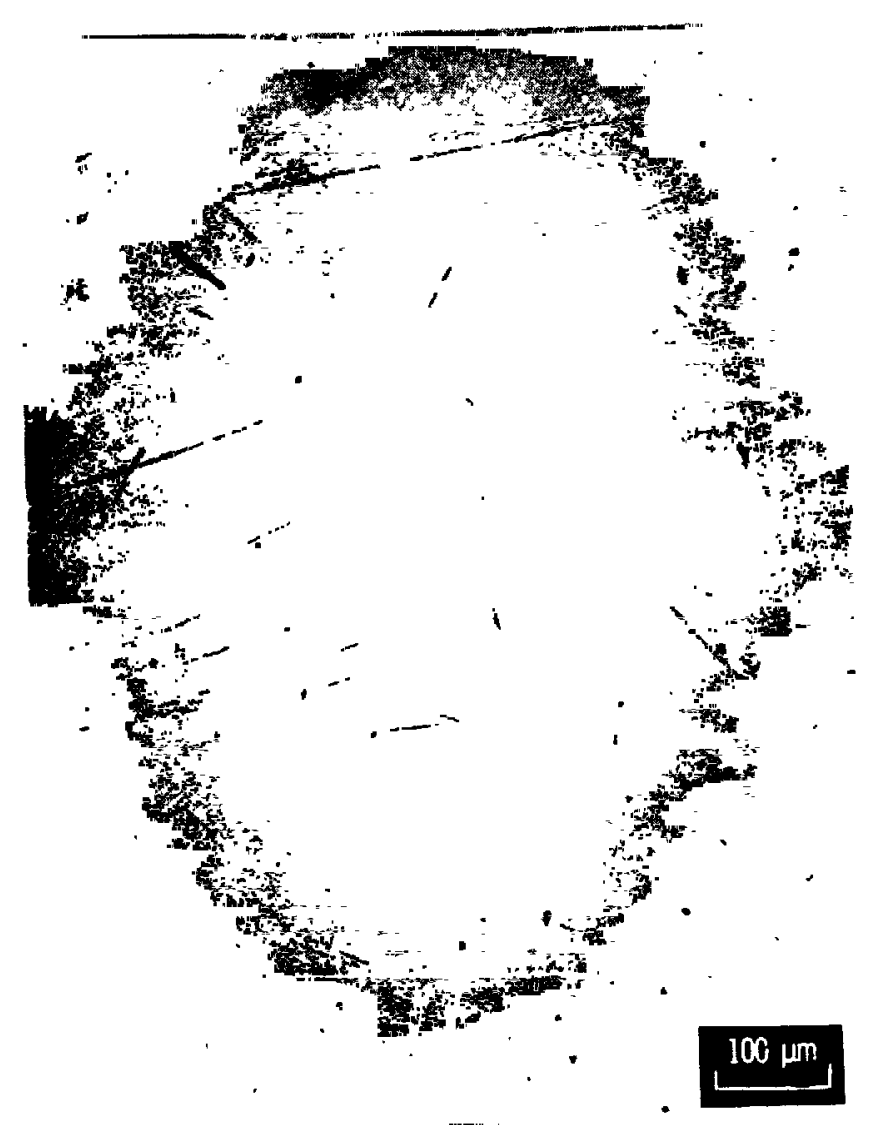

Figure 18. - Deep groove made with sharp wedge-shaped tool.

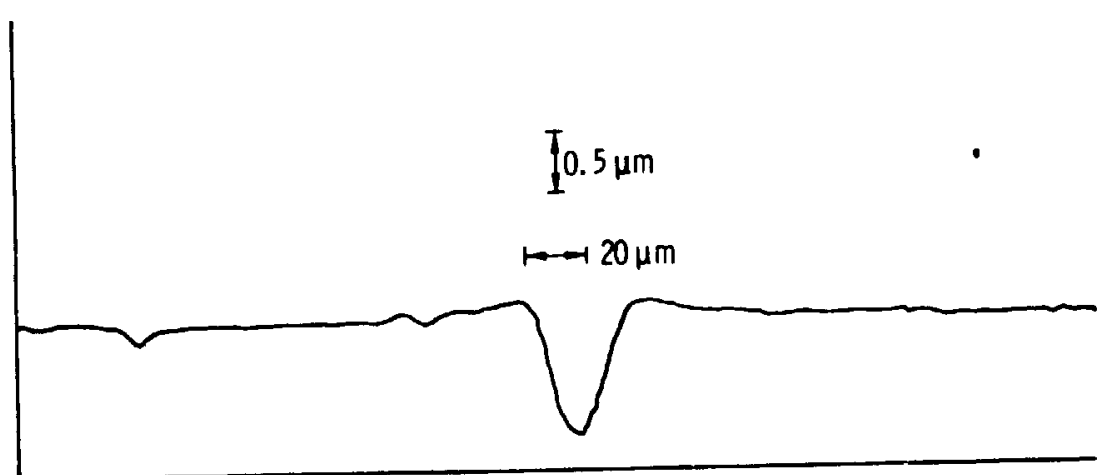

Figure 19. - Stylus trace of deep groove. 


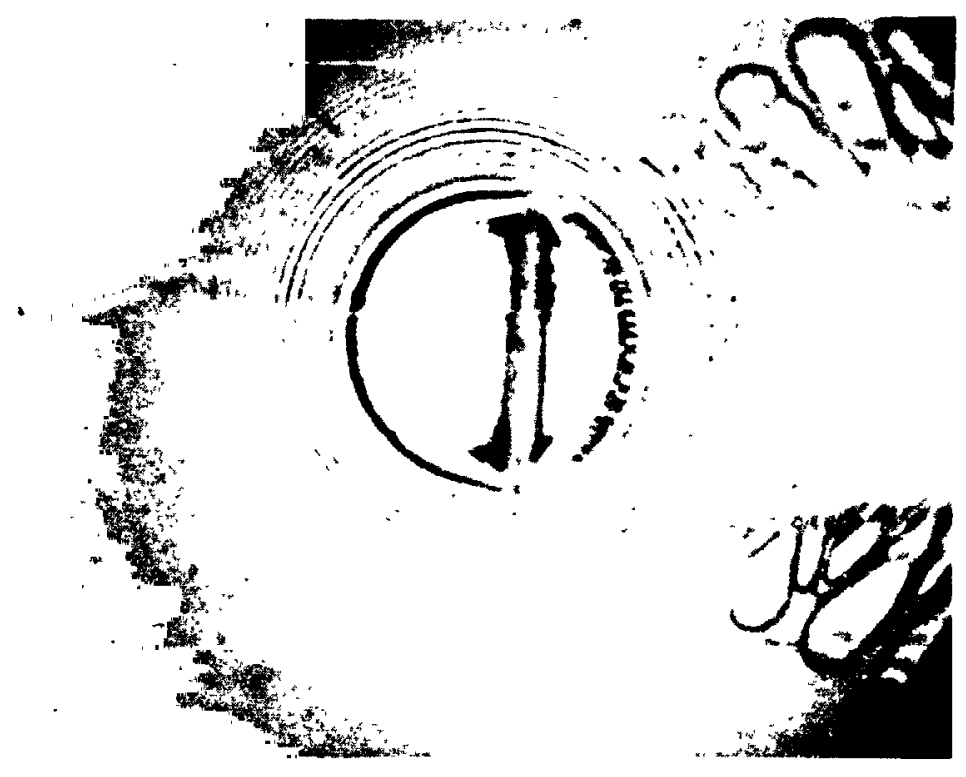

Figure 20. - Photomicrograph of deep groove; rolling. $U \cdot 0.0134 \mathrm{M} / \mathrm{S}$, $P_{\max } \cdot 1.13 \times 10^{9} \mathrm{~N} / \mathrm{M}^{2}$.

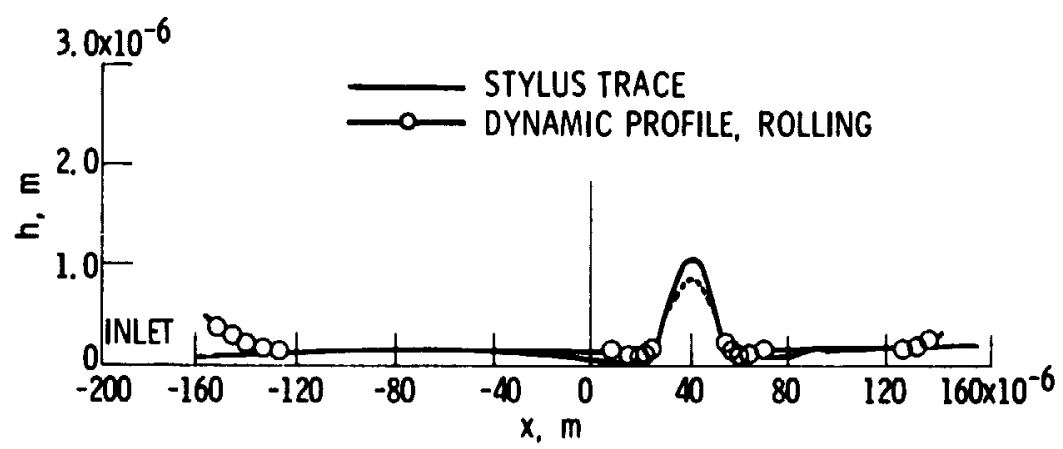

Figure 21. - Comparison of stylus trace of deep groove with dynamic protile under rolling conditions. 


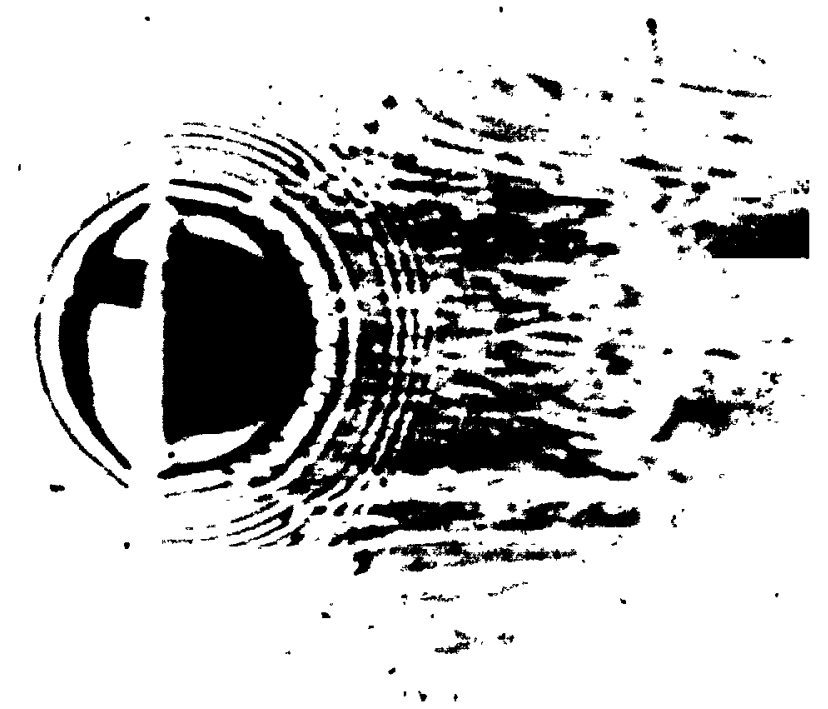

Figure 22. - Photomicrograph of deep groove under sliding conditinns. $U \cdot 0.0134 \mathrm{M} / \mathrm{S}, P_{\operatorname{miax}} \cdot i .13 \times 10^{9} \mathrm{~N}^{\mathrm{M}} \mathrm{M}^{2}$.

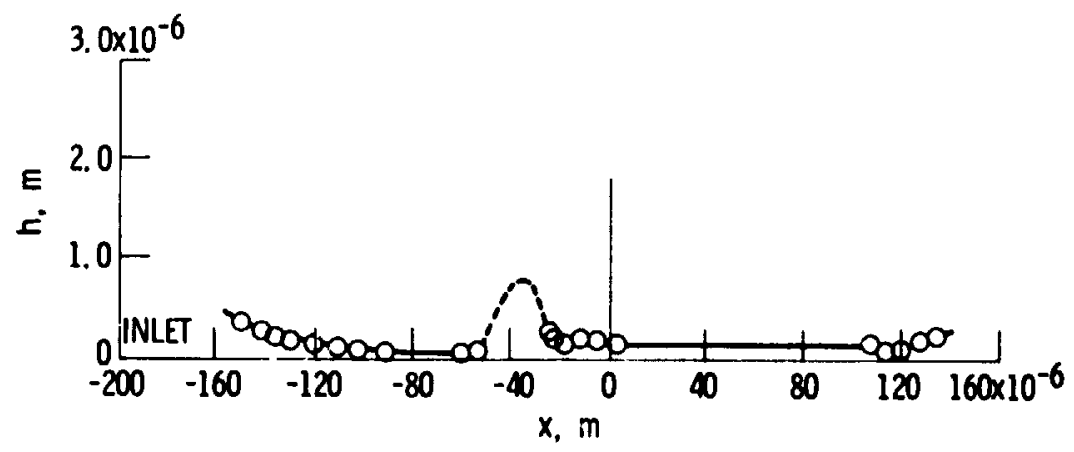

Figure 23. - Cross-sectional profile of deep groove in figure 22. 


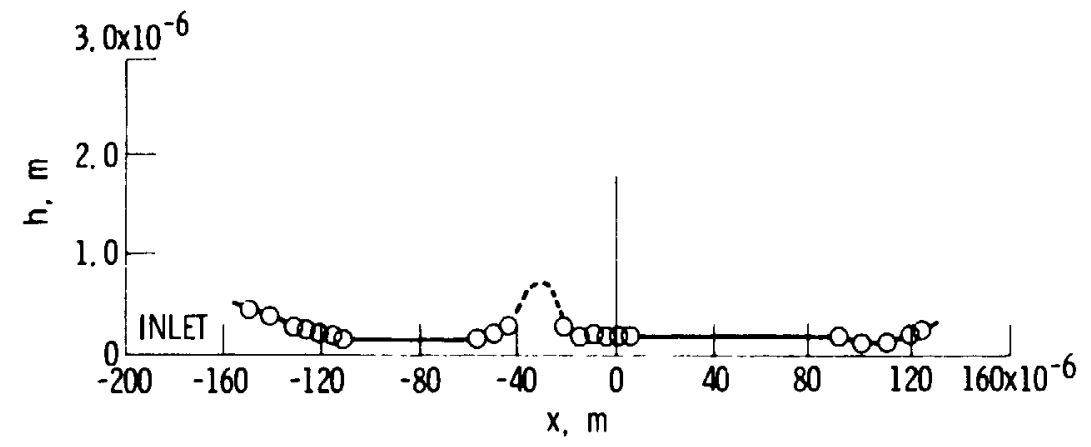

Figure 24. - Cross-sectional profile across portion of groove in figure 22 which does not show reduced film thickness at trailing edge.

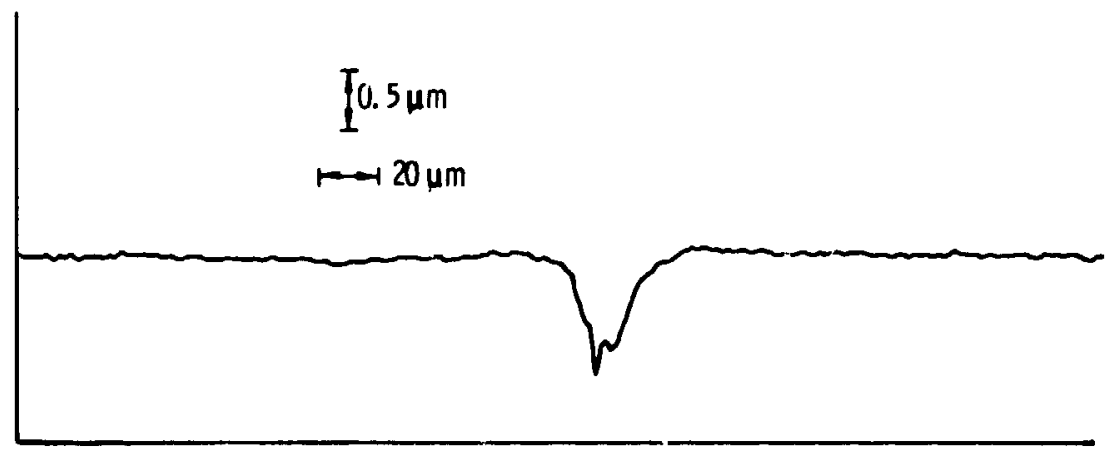

Figure 25. - Stylus trace across portion of groove showing rounded shoulders. 


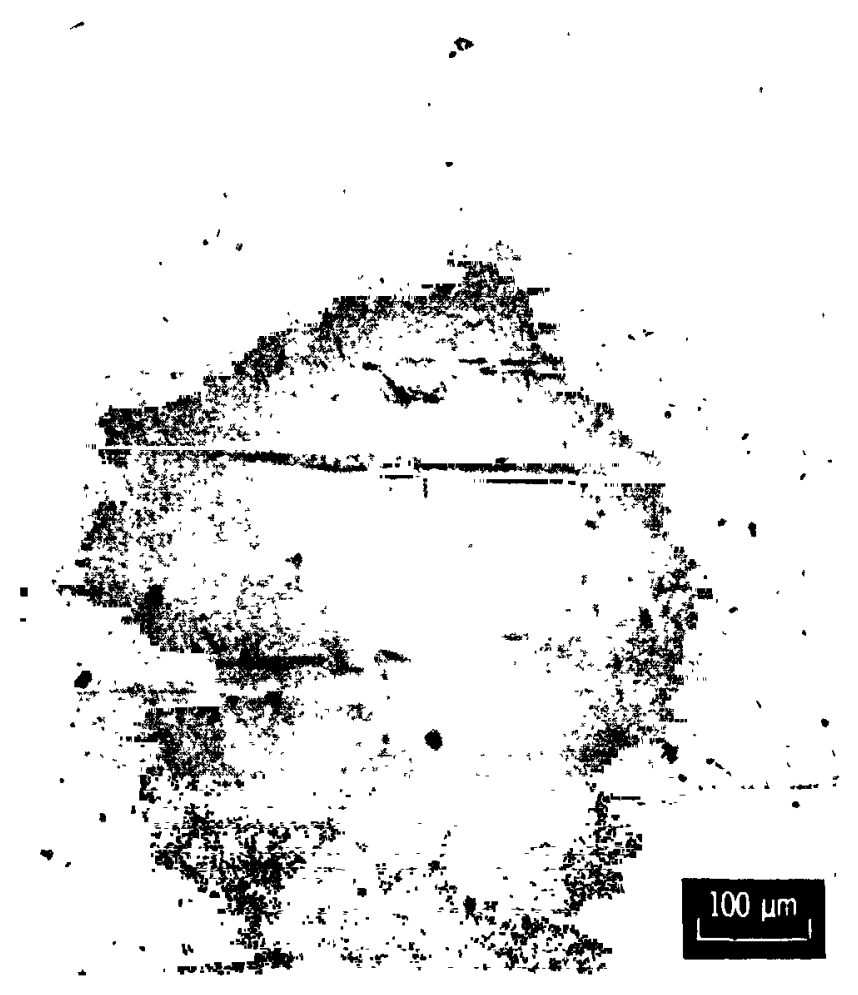

Figure 26. - Groove made with wedge-shaped tool oriented parallel to the direction of flow.

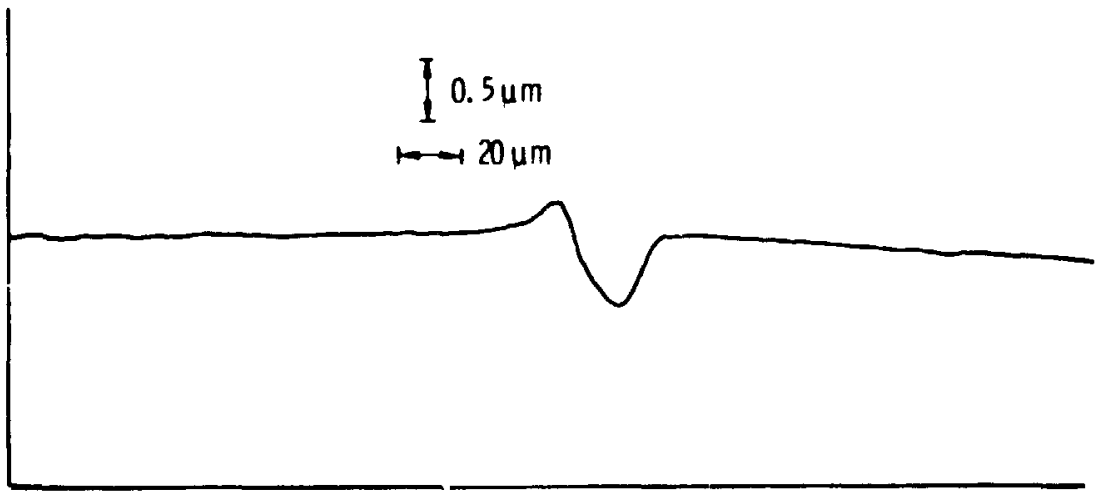

Figure 27. - Stylus trace of groove in figure 26 . Trace taken perpendicular to flow direction. 


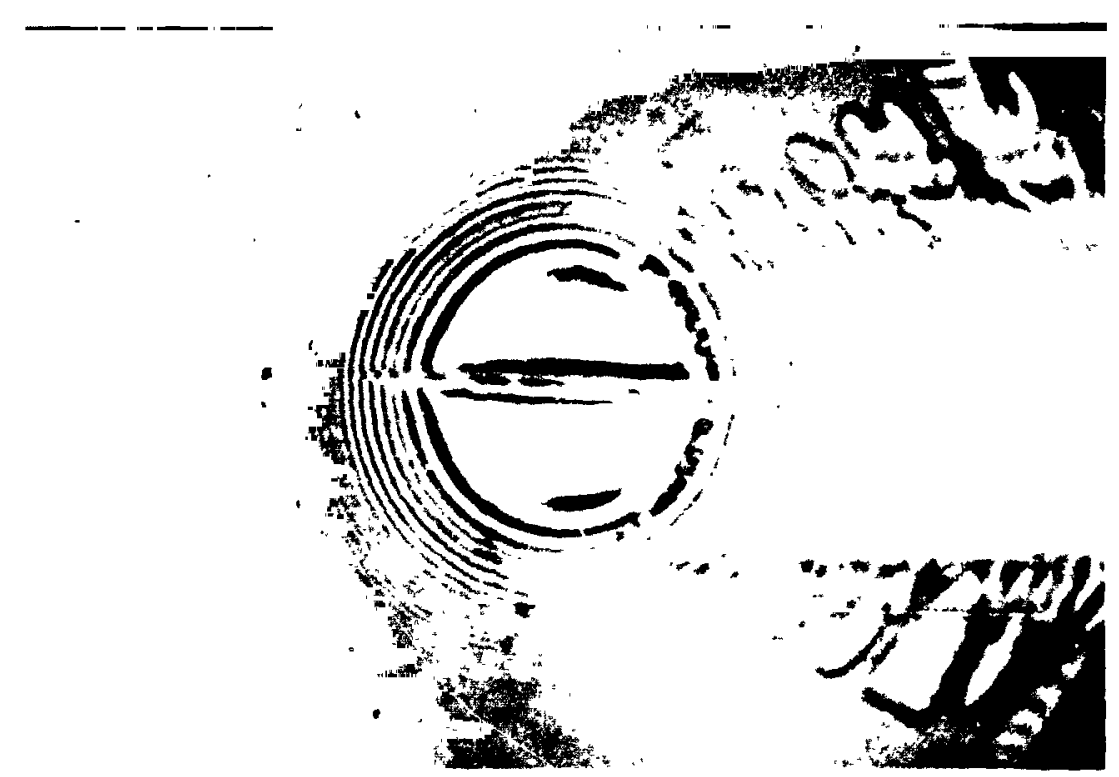

Figure 28. - Photomicrograph of groove oriented parallel to flow direction. $U \cdot 0.0134 \mathrm{M} / \mathrm{S}, P_{\max }=1.13 \times 10^{9} \mathrm{~N} / \mathrm{M}^{2}$.

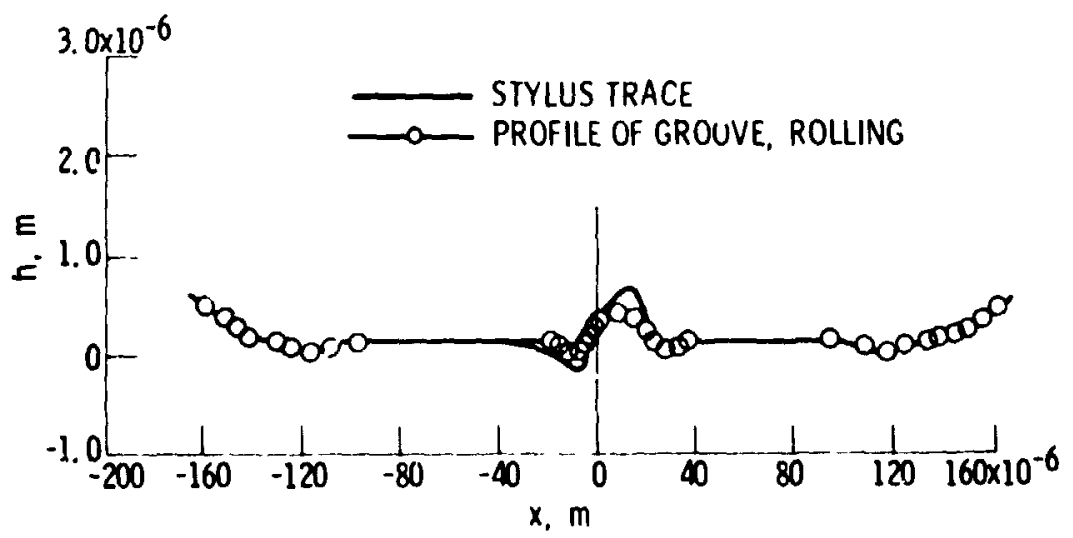

Figure 29. - Comparison of stylus trace of groove oriented parallel to the flow direction with dynamic profile under roliing conditions. 


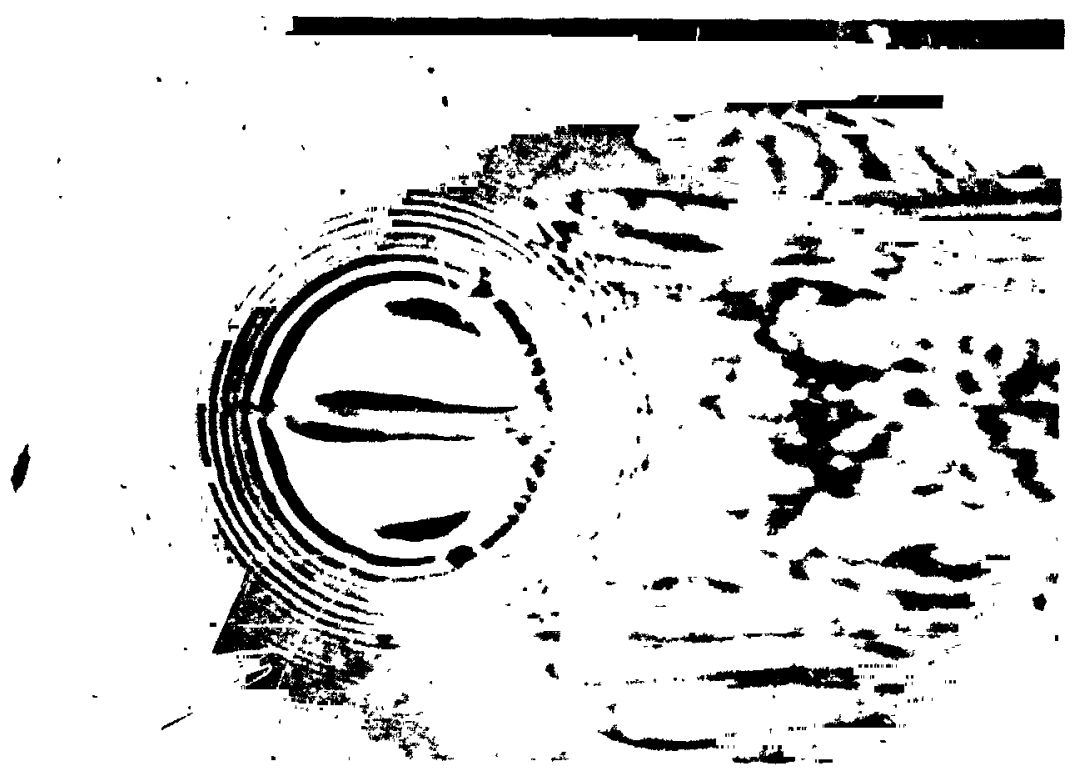

Figure 30. - Photomicrograph of groove under sliding conditions. $U$ $0.0134 \mathrm{M} / \mathrm{S}, P_{\max }=1.13 \times 10^{9} \mathrm{~N} / \mathrm{M}^{2}$.

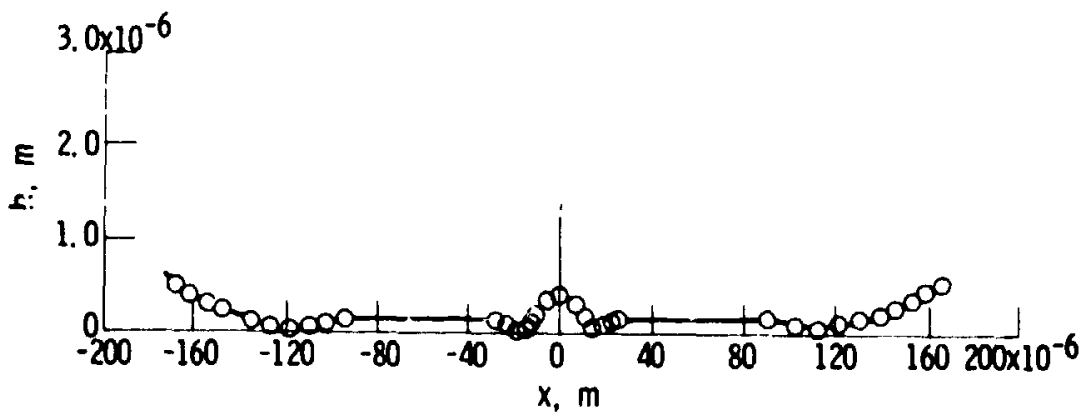

Figure 31. - Cross-sectional plot (perpendicular to flow dirertion) of groove in figure 30. 


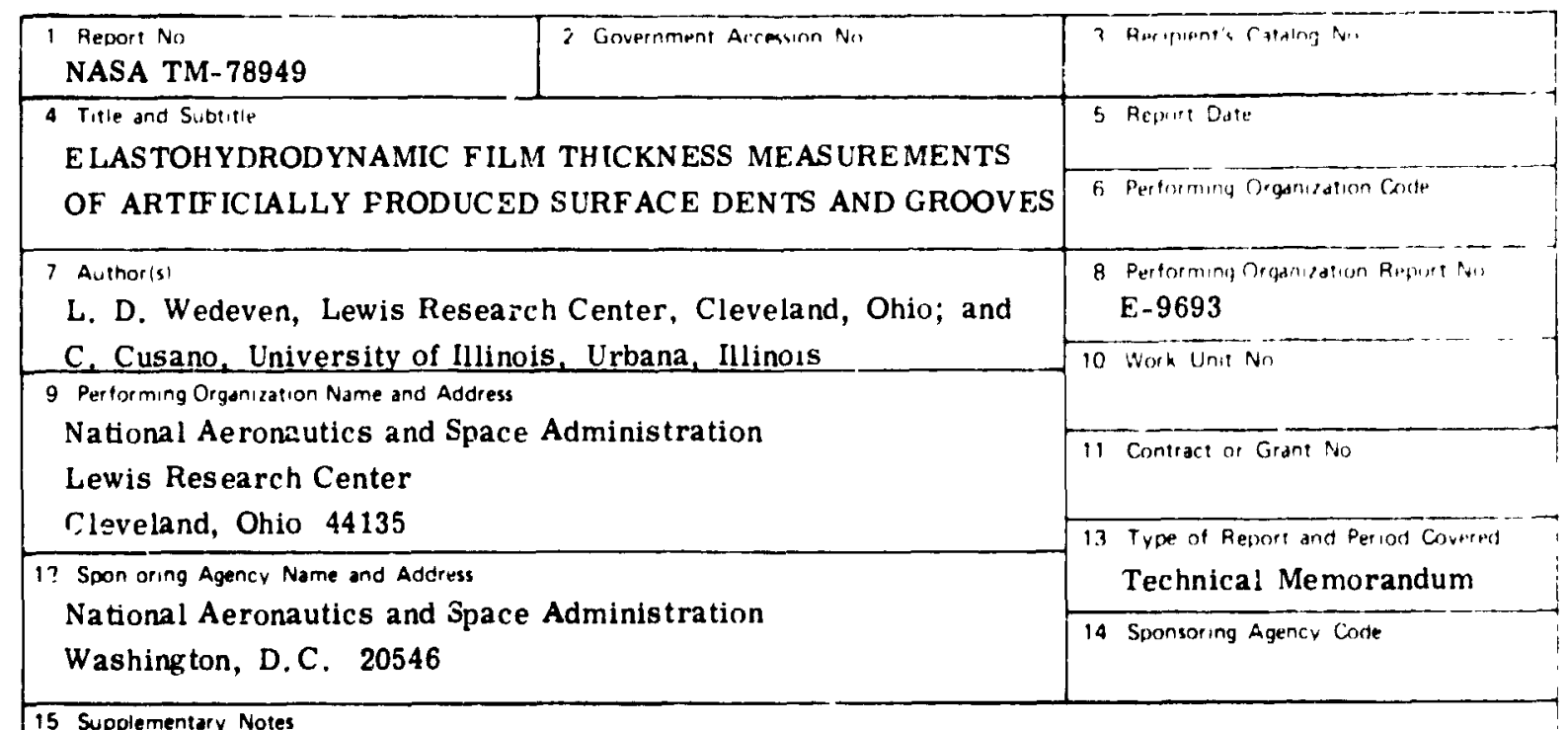

15 Supplementary Notes

16 Abstract

Elastohydrodynamic (EHD) film thickness measurements using optical interferometry have been made of artificially produced dents and grooves under rolling and sliding conditions. These measurements are compared to stylus traces of the dent and groove profiles to determine the local deformation associated with micro-EHD pressure generation. The surface geometry associated with the dents and grooves is seen to become intimately involved in the lubrication process itself, creating local pressure variations that substantially deform the local surface geometry, particularly under sliding conditions. The rolling results have implications concerniry surface initiated fatigue and the sliding results show clearly the EHD surface interactions that must occur prior to scuffing failure.

\begin{tabular}{|c|c|c|c|c|}
\hline \multicolumn{2}{|l|}{$\begin{array}{l}\text { 17. Key Words (Suganted by Author(s)) } \\
\text { Elas tohydrodyna mics } \\
\text { Film thickness } \\
\text { Bearing surface defects }\end{array}$} & \multicolumn{3}{|c|}{$\begin{array}{l}18 \text { Distribution Statement } \\
\text { Unclassified - unlimited } \\
\text { STAR Category } 37\end{array}$} \\
\hline $\begin{array}{l}10 \text { Securiey Clesuf lot inis report) } \\
\text { Unclassifled }\end{array}$ & $\begin{array}{r}20 \text { Security Classit lof th } \\
\text { Unclas }\end{array}$ & $\begin{array}{l}\text { this pigal } \\
\text { lestlfed }\end{array}$ & 21 No of Pages & 22 Pice" \\
\hline
\end{tabular}

- For sale by the National Technical Information Service Smrngtield Virg!nia 22161 